No. 1738

December 2020

\title{
Quantifying the externalities of renewable energy plants using wellbeing data: The case of biogas
}

Christian Krekel

Julia Rechlitz

Johannes Rode

Alexander Zerrahn 


\begin{abstract}
Although there is strong support for renewable energy plants, they are often met with local resistance. We quantify the externalities of renewable energy plants using well-being data. We focus on the example of biogas, one of the most frequently deployed technologies besides wind and solar. To this end, we combine longitudinal household data with novel panel data on more than 13,000 installations in Germany. Identification rests on a spatial difference-in-differences design exploiting exact geographical coordinates of households, biogas installations and wind direction and intensity. We find limited evidence for negative externalities: impacts are moderate in size and spatially confined to a radius of 2, 000 metres around plants. We discuss implications for research and regional planning, in particular minimum setback distances and potential monetary compensations.
\end{abstract}

Key words: renewables, biogas, externalities, social acceptance, wellbeing, spatial analysis, economic geography

JEL codes: C23; Q42; Q51; R20

This paper was produced as part of the Centre's Community Wellbeing Programme. The Centre for Economic Performance is financed by the Economic and Social Research Council.

Christian Krekel, London School of Economics and Centre for Economic Performance, London School of Economics. Julia Rechlitz, German Institute for Economic Research. Johannes Rode, Technical University of Darmstadt. Alexander Zerrahn, German Institute for Economic Research.

Published by

Centre for Economic Performance

London School of Economics and Political Science

Houghton Street

London WC2A 2AE

All rights reserved. No part of this publication may be reproduced, stored in a retrieval system or transmitted in any form or by any means without the prior permission in writing of the publisher nor be issued to the public or circulated in any form other than that in which it is published.

Requests for permission to reproduce any article or part of the Working Paper should be sent to the editor at the above address.

(C) C. Krekel, J. Rechlitz, J. Rode and A. Zerrahn, submitted 2020. 


\section{Introduction}

Renewables play an ever-increasing role in electricity generation. Increasing the share of renewables is a key element in many countries' strategies to combat climate change, since they help avoid negative externalities associated with conventional technologies, especially greenhouse gas emissions from fossil fuel combustion. Globally, the share of renewables excluding hydropower grew from $1.3 \%$ in 1990 to $9.3 \%$ in 2018 (IEA, 2020).

With a growing awareness of the negative consequences of greenhouse gas emissions in the population, global support for renewables is strong (e.g., see PEW Research Center (2016) for the U.S., or Umweltbundesamt (2019) for Germany). However, renewable energy plants, which are spatially more dispersed and more closely located to places of residence than conventional plants, are often met with local resistance. Local residents fear the potential negative externalities of renewable energy plants nearby. This phenomenon is referred to as not-in-my-backyard (NIMBY) effect and is counter to countries' efforts to enhance the deployment of renewables in electricity generation. In this paper, we quantify the externalities of renewable energy plants by the example of biogas plants in Germany. We analyze how individuals' subjective wellbeing is affected by a newly constructed biogas plant nearby using a difference-in-differences approach to establish causality. Our empirical analysis rests on a newly constructed and comprehensive data set on individuals covering the years 2000 to 2012.

Biomass plants play an important role in integrating other renewables into the electricity system. Because electricity generation from biomass, unlike solar and wind, does not depend on exogenous and variable weather conditions, it can be scheduled when needed or profitable. Since 2010, worldwide capacities for electricity generation from biomass have almost doubled, reaching over 120 gigawatt (GW) in 2019 (IRENA, 2020). Amongst them, biogas plants play a particularly large role. In Germany, there 
was an overall installed capacity of around 10 GW in 2019, which had a share of $5 \%$ on the gross electricity consumption (BMWi, 2020).

Biogas plants ferment biological inputs to produce flammable gas, which is then combusted, generating electricity and heat. Contrary to coal or natural gas, it is largely climate-friendly. While its combustion releases $\mathrm{CO}_{2}$, the biological inputs feeding the plant previously absorbed roughly the same amount from the atmosphere. ${ }^{1}$ However, other potential externalities of biogas plants are often quoted as the root source for local resistance against new installations.

First, odour emissions may stem from transport and storage of inputs such as liquid manure, inappropriate operation of installations, or application of inadequately fermented waste materials on nearby fields (BSOE, 2011). Second, the operation can increase the traffic volume of inputs towards and waste materials from plants. Third, installations can be large and may thus interfere with landscape aesthetics and growing energy crops such as maize may lead to uniform, monoculture landscapes. ${ }^{2}$ Finally, the application of waste materials on nearby fields may lead to a heightened nitrate concentration in groundwater.

Not surprisingly then, in 2013, a survey among 6,500 German households found that biogas is by far the most unpopular renewable energy source (Andor et al., 2015). Another survey by Meyerhoff et al. (2015) finds that only 51\% of 3,180 interviewed individuals report being supportive to a new biogas plant built within $10-\mathrm{km}$ distance to their home, compared to $89 \%$ for solar and $72 \%$ for wind. The stated willingness to protest against a new installation is also considerably higher: $25 \%$ of residents state

\footnotetext{
${ }^{1}$ In Germany, one megawatt hour of electricity generated from biogas is estimated to have crowded out roughly 400 kilogram of $\mathrm{CO}_{2}$ equivalents in 2014 (BMWi, 2017).

${ }^{2}$ There is also a growing fear of genetically modified maize, which is often used as an input, while externalities on agriculture or deforestation may not only be local but also occur in distant places (Keles et al., 2017).
} 
that they would be willing to engage in active protest against biogas, compared to $8 \%$ for solar and $17 \%$ for wind (Meyerhoff et al., 2015). ${ }^{3}$

To study the potential negative externalities of biogas plants systematically, we analyse longitudinal household data with a novel panel of more than 13,000 biogas plants in Germany. Germany is an ideal case study for this purpose: the country is considered to be a role model in the transition towards renewables. The Renewable Energy Source Act (Erneuerbaren Energien Gesetz - EEG), which came into force in March 2000, has supported the expansion of different renewable energy technologies implementing fixed feed-in-tariffs for electricity generation. Feed-in-tariffs also benefited biogas plants ${ }^{4}$ resulting in a steadily rising installed capacity of biogas plants in our observation period (BMWi, 2020).

We quantify negative externalities in two steps: first, we estimate the causal effect of newly constructed biogas plants in households' surroundings on the wellbeing of household members. Identification rests on a spatial difference-in-differences design exploiting exact geographical coordinates of households and installations. We illustrate that our treatment and our control group follow a common trend before the treatment. We then trade off the impact of biogas plants on household members' wellbeing with that of income. This is referred to as experienced-preferences approach (Welsch and Kühling, 2009; Welsch and Ferreira, 2014), to distinguish it from stated-preference approaches such as contingent valuation or discrete choice experiments and revealedpreference approaches such as hedonic pricing. It has become a common method to value intangibles such as air pollution (Levinson, 2012; Ferreira et al., 2013; Ambrey et al., 2014), noise pollution (van Praag and Baarsma, 2005; Rehdanz and Maddison,

\footnotetext{
${ }^{3}$ Similarly, Dobers (2019) finds that only $44 \%$ of the survey participants somewhat support or strongly support the construction of a biogas plant within a $10 \mathrm{~km}$ radius of their place of residence. The finding relies on 942 respondents from a survey conducted in Germany in 2013.

${ }^{4}$ Only biogas plants with an installed capacity below $20 \mathrm{MW}$ benefited from the fixed feed-in-tariffs.
} 
2008), landscape amenities (Kopmann and Rehdanz, 2013), land use (Bertram and Rehdanz, 2015; Krekel et al., 2016; Bertram et al., 2020), flood disasters (Luechinger and Raschky, 2009), mega events (Dolan et al., 2019), or energy infrastructure externalities (Krekel and Zerrahn, 2017; von Möllendorff and Welsch, 2017).

We find limited evidence on the negative externalities of biogas plants: the construction of a new installation inside a 2,000 metres radius around a household reduces the self-reported life satisfaction of household members by about $8 \%$ of a standard deviation, an impact of moderate size. Impacts are also spatially limited, being undetectable for a distance larger than 2,000 metres. Our findings therefore suggest a minimum setback distance of 2,000 metres between households and the nearest installation. Assuming no habituation, we arrive at a willingness-to-pay to avoid a new installation inside a 2, 000 metres radius around their households of about 6, 900 EUR (8, 120 USD) per individual per year or 575 EUR (677 USD) per individual per month. ${ }^{5}$ As there are, on average, 3.1 individuals per household in our estimation sample, this yields 1,783 EUR (2, 098 USD) per household per month. Compared with the estimated negative externalities of wind turbines, the externalities of biogas plants are considerably smaller. ${ }^{6}$

Our results are robust in several dimensions. We conduct a placebo test and use worries about crime as an alternative outcome. As expected, we do not find any effects on this exercise. We also use worries about health as an outcome. A biogas plant increases the likelihood that respondents are worried about their health by about four percentage points. This may point towards presumed negative impacts of biogas plants on the health of nearby residents, suggesting a potential mechanism through which impacts on wellbeing may come about. However, we fail to detect significant impacts

\footnotetext{
${ }^{5}$ Using an exchange rate of $1: 1.18$ as of July $29,2020$.

${ }^{6}$ Krekel and Zerrahn (2017) find that a wind turbine nearby reduces self-reported life satisfaction by about $11 \%$ of a standard deviation.
} 
on a range of physical and mental health outcomes obtained from the Short-Form (SF12) Health Survey, suggesting that nuisance, rather than health, is driving negative wellbeing impacts.

\section{Biogas Plants and Externalities}

Biogas plants use energy crops such as maize, remnant materials from livestock farming (predominantly liquid manure), or green waste from agriculture as inputs into a fermentation process. In this process, bacteria decompose these inputs. The resulting flammable gas, the most important component of which is methane, is then combusted in an on-site combined thermal power station to generate electricity and heat for nearby households. Digested residues are temporarily stored and typically re-used as fertilisers in nearby agriculture.

Although installations can be large, the construction process typically takes less than a year, even for industrial installations. Plants are normally delivered turnkey by specialist providers. Biogas plants play an essential role in supporting the integration of fluctuating renewables into the electricity system. Biogas plants are mostly climate-friendly, do not depend on exogenous weather conditions, and hence are socalled dispatchable. But biogas plants are not entirely free of negative externalities themselves. Odour emissions typically stem from transport (high traffic volume may constitute an externality in itself) and storage of inputs, or from the inappropriate operation of installations. Residues that are spread on the surrounding field may also lead to a heightened nitrate concentration in groundwater. Furthermore, biogas plants might change the landscape. It can foster the cultivation of energy crops such as maize, leading to a more monocultural landscape. Also, the power plant itself can interfere with the landscape. 
For a typical biogas plant in our sample, see Figure 1: the plant started operation in July 2008 after a construction period of seven months. Costs were about three million EUR (3.5 million USD). Inputs are energy crops (maize, rye, millet, and beets), delivered by up to 50 farmers nearby (digested residues are later returned to them to be re-used as fertilisers on their fields). Annually, the plant consumes about 13,000 tons of inputs, from which it produces about 8.3 gigawatt hours (GWh) of electricity and about the same amount of heat (Groß-Gerau Online, 2018).

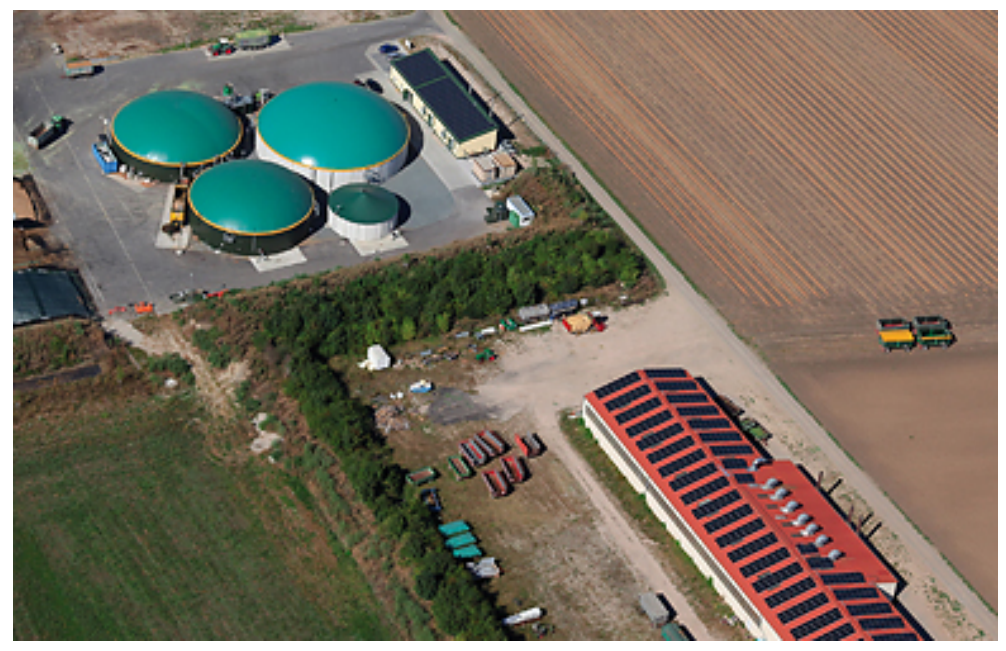

Figure 1: A typical biogas plant in our sample Source: (Überlandwerk Groß-Gerau GmbH, 2018)

\section{Previous Evidence}

In the stated-preferences literature, evidence on externalities of biogas plants is scant and, if anything, case-study based rather than systematic. Most studies point toward negative externalities and public attitudes.

Schumacher and Schultmann (2017) conducted a cross-country survey of 667 residents living near 11 biogas plants in France, Germany, and Switzerland. The majority of respondents rate the plant in their surroundings as negative, and most state they 
would be willing to oppose a new installation actively. Only $19 \%$ are willing to live inside a one kilometre radius. Most consider a minimum distance between three and eight kilometres as acceptable. Perceived odour emissions decrease acceptance considerably, while visual contact seems less critical. Some also report a loss in quality of life. Similar findings are obtained for Germany (Zoellner et al., 2008; Wüste and Schmuck, 2013; Bertsch et al., 2016; Dobers, 2019), Switzerland (Soland et al., 2013), and the UK (Upreti, 2004; Upreti and van der Horst, 2004; Upham and Shackley, 2006, 2007; Upham, 2009).

Stated-preferences approaches directly ask respondents about their attitudes towards the technology in general, a particular plant, or a hypothetical or planned new installation. This can be problematic: the complexity and cognitive burden of valuing hypothetical scenarios may yield biased statements. Likewise, symbolic valuation consciously or subconsciously - may yield expressions of attitudes rather than preferences. Studies can be prone to framing and anchoring (Kahneman and Sugden, 2005), and respondents may have incentives to answer in a strategical or socially desirable way, especially when interviewers are present.

An alternative is revealed-preferences approaches such as hedonic pricing: here, externalities are valued using observed changes in real estate prices resulting from new installations. Modica (2017) uses a difference-in-differences design covering the period 2006 to 2015 in which 167 new biogas plants were built in Piedmont, Italy. The author does not find that new installations have negative effects on house prices. Pechrova and Lohr (2016), using simple hedonic regression, find small effects on rental prices for eight installations in the Czech Republic: decreasing the distance to the nearest installation by one kilometre (the mean distance is about 8.4 kilometres) decreases rental prices by $0.15 \%$ to $0.40 \%$. Zemo et al. (2019) investigate large and small biogas plants in Denmark. The authors find that a $1 \%$ increase in distance to a large biogas plant is 
associated with an increase of $0.07 \%$ in rural house prices. In contrast, a $1 \%$ increase in distance to a small scale biogas plant is associated with a $0.08 \%$ decrease in rural house prices.

For real estate prices to fully reflect externalities, markets need to be in equilibrium. Frictions such as slow price adjustment, incomplete information, transaction costs (especially direct and indirect moving costs), or systematic misprediction of future utility associated with moving (see Krekel and Odermatt (2019) for evidence) may violate this condition. Finally, depending on location, real estate markets may not be dynamic: this may be especially true in rural areas where only little transactions occur.

The experienced-preferences approach may overcome some of these issues: here, selfreported life satisfaction - which Kahneman et al. (1997) refer to as experienced utility - is regressed on a dummy for biogas plants, alongside confounders including rental prices. The marginal rate of substitution between plants and income then yields a monetary valuation of their externalities, net of what has been internalised through real estate prices. The relationship of interest itself remains covert to respondents, reducing incentives to answer in a strategic or socially desirable way.

The paper most closely related to ours is von Möllendorff and Welsch (2017): the authors study the relationship between renewable energy plants and nearby households' wellbeing. The major finding is that biogas plants are associated with lower household wellbeing. However, the study differs from ours in several aspects: most importantly, the authors do not use a control group with which the impacts on the treatment group can be compared. Therefore, the analysis reveals correlations only. Moreover, the study relies on the post-code level, which is a wider geographical area. 


\section{Data}

\subsection{Household Data}

The German Socio-Economic Panel Study (SOEP) is a representative panel of private households in Germany (SOEP, 2015). It has been conducted annually since 1984 and contains almost 30, 000 individuals in more than 11,000 households in its most current wave (Wagner et al., 2007, 2008). Importantly, it provides the exact geographical coordinates of households in every survey year since 2000. This allows merging household data with data on biogas plants based on geographical information and timing.7

Our main outcome is satisfaction with life. To assess individuals' life satisfaction, respondents answer the question "How satisfied are you with your life, all things considered?" on an eleven-point single-item Likert scale where zero denotes "completely dissatisfied" and ten "completely satisfied". As an evaluative measure of subjective wellbeing, life satisfaction can be defined as a cognitive evaluation of the circumstances in life relative to an ideal life (Diener et al., 1999). ${ }^{8}$

In our analysis, we use a wide range of observables stemming from the SOEP. At the individual and household level, controls include demographic and human capital characteristics as well as economic and housing conditions. At the NUTS-3 region level, controls include the unemployment rate and average income. Table A.1 in the Appendix shows summary statistics for our household data.

\footnotetext{
${ }^{7}$ The SOEP is subject to strict data protection: it is not possible to derive household data from geographical coordinates as they are never visible to the researcher at the same time. See Goebel and Pauer (2014) for details.

${ }^{8}$ There is an ongoing debate about whether life satisfaction is equal to utility or just one component, amongst others, in an individual's utility function (Becker and Rayo, 2008; Benjamin et al., 2012; Glaeser et al., 2016). This debate is of secondary importance here: we are not interested in life satisfaction per se but to use it as a vehicle to detect and value externalities. By and large, individuals make choices that are consistent with maximising life satisfaction (Adler et al., 2017).
} 


\subsection{Data on Biogas Plants}

Our study builds on official biogas plant data from the German electricity transmission system operators. They include all 13, 492 biogas plants connected to the grid through the end of 2012. ${ }^{9}$ Besides others, this data set contains information on the location of the power plant, the date of operation, and further details on the fuel type and plant size.

Since our identification strategy rests on the exact location of biogas plants and households, we need to specify the geographical coordinates in great detail. The Anlagenstammdaten contains address information which we convert into geographical coordinates. These coordinates are accurate for the majority of plants.

However, about a third of the installations have only approximate accuracy, meaning that inferred coordinates can be more than one hundred metres away from the actual site. For such plants, we manually check addresses using satellite imagery. We increase the accuracy for more than a third of them by eliminating obvious typing or locational errors. To improve the accuracy of the site data of the remaining biogas plants, we use the geographical coordinates from the German registry of renewable energy plants (Anlagenregister) from 2016, if available. The Anlagenregister only contains information on plants for which certain regulatory changes applied between 2014 and 2016. ${ }^{10}$ We also validate our data against data from the International Solar Energy Society, which collected data from the official registry of renewable energy plants, carried out extensive checks, and published the improved data. ${ }^{11}$ Whenever we detect significant differences

\footnotetext{
${ }^{9}$ We downloaded the raw data - the Anlagenstammdaten - from http: //www.netztransparenz.de on September 8, 2014. The Anlagenstammdaten are the official account of all renewable energy plants in Germany.

${ }^{10}$ The Anlagenregister was downloaded from http://www.bundesnetzagentur.de/DE/ Sachgebiete/ElektrizitaetundGas/Unternehmen_Institutionen/ErneuerbareEnergien/ ZahlenDatenInformationen/EEG_Registerdaten/EEG_Registerdaten_node.html on August $29,2016$.

${ }^{11}$ The data were downloaded from http://www.energymap.info on October 24, 2016.
} 
between these data and ours, we check addresses using satellite imagery and update our data if necessary. All biogas plants which still have only locational information with approximate accuracy are flagged as data deficient.

Moreover, we classify plants as data deficient, when our different data sources provide significantly different information on plant size, fuel type, or the date of operation. ${ }^{12}$ Plants classified as data deficient receive special attention in defining our treatment and control group, as Section 5.1 explains.

Finally, we exclude small biogas plants with an installed capacity below 150 kilowatts $(\mathrm{kW})$ as well as installations at which biogas is exclusively drawn from the natural gas grid as we expect them to have only negligible externalities.

After carrying out plausibility checks on all variables for a random draw of plants, we arrive at a new and comprehensive panel of more than 10,000 biogas plants in Germany with grid connection through the end of 2012 at a high-quality level. Figure 2 illustrates the geographical distribution of these plants.

We merge our household data with our data on biogas plants using geographical coordinates. This allows us to calculate the exact distance between each household and each plant in its surroundings. Tables A.2 to A.4 in the Appendix show summary statistics for our data on biogas plants.

\subsection{Data on Wind}

Wind directions come from NASA's MERRA-2 database that provides long-running, fine-grained time series for a range of meteorological and climate indicators based on re-analysis of satellite observational data (Gelaro et al., 2017). The MERRA data are

\footnotetext{
${ }^{12}$ We define a plant as data deficient when 1) their installed capacity is at least once reported to be less than 75 kilowatts and once to be greater than this threshold or 2) two data sources report different fuel types, or 3) the divergence in the date of operation is larger than 30 days. Note that the date of operation is defined by the date at which feed-in tariffs are paid to the operator for the first time, which should be the first day of operation when potential externalities associated with the normal operation of the plant should arise for the first time.
} 


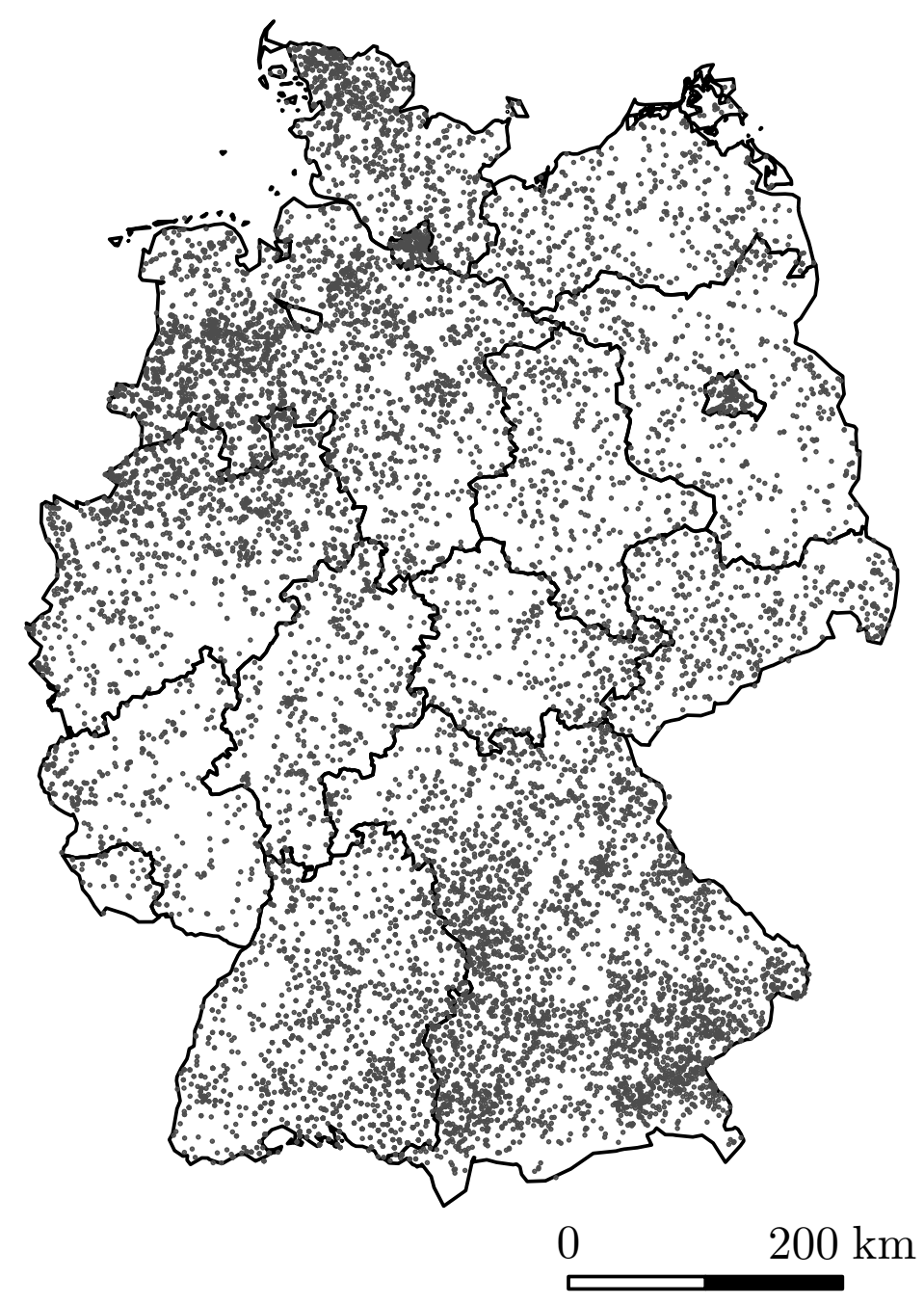

Figure 2: Biogas plants with grid connection in Germany through the end of 2012. Dots are biogas plants, lines are borders of federal states.

Source: Data on biogas plants as described in Section 4.2

widely used in climate and energy-related studies. Specifically, we use a dataset on wind directions in ten metres over ground (Global Modeling and Assimilation Office (GMAO), 2015). The raw data have an hourly resolution over the entire analysis period and a spatial resolution of 0.5 degrees latitude $\times 0.625$ degrees longitude. For Germany, this amounts to tiles of roughly $55 \times 40$ kilometres. We allocate each household to the nearest tile using its centroid. 


\section{Empirical Strategy}

\subsection{Treatment and Control}

A household, including all its members, is allocated to the treatment group if a biogas plant is newly constructed inside a pre-specified treatment radius during the observation period. The treatment radii 1,000, 1,500, 2,000, 2, 500, and 3, 000 metres define the neighbourhood of a household. We select different treatment radii for several reasons.

First, analysing different treatment radii allows investigating the geographical range of potential externalities. Second, there exists no uniform legislation in Germany that could serve as a point of reference. Environmental impact assessments of new installations are both location-specific and plant-specific, with impact radii varying across federal states and between survey years. ${ }^{13}$

We define minimum requirements for a biogas plant to trigger treatment. Only plants which were not previously classified to be "data deficient" can trigger a treatment. To be conservative, plants that do not trigger treatment are instead triggering the exclusion of a household, if such plants are observed previous to plants that do trigger treatment. Put differently, when a plant, e.g. with inaccurate geographical information, is constructed "close" to a household, we cannot be certain whether it affects household members, and therefore exclude the respective household. In a sensitivity analysis, we relax these conservative requirements and assume that data deficient, small, and only approximately localised plants trigger treatment (which produces similar estimates

\footnotetext{
${ }^{13}$ There exists no legal mandate for a minimum setback distance between installations and neighbouring residential areas in Germany. Rather, this is a case-by-case decision, depending on fuel type and plant size, availability of a development plan, specific location, type of building area, type of neighbouring residential area, and whether the installation is located inside an inner or an outer zone under German building law. See Administrative Court Munich (2016), for example. The Biogas Handbook for Bavaria (Biogashandbuch Bayern) specifies minimum setback distances between 300 and 500* metres for open and closed installations, respectively, but installations can fall below these distances under certain technical conditions (BSOE, 2011).
} 
as our baseline specification). ${ }^{14}$ Finally, we exclude households that already had a plant in their vicinity before the beginning of the observation period. Otherwise, these previously treated households would have entered the control group.

To obtain a clear-cut distinction between treatment and control group, we add a constant ban radius of 3,000 metres. $^{15}$ Figure 3 illustrates this setup: households that have no plant inside the treatment radius but a plant inside the ban radius are neither assigned to treatment nor control; they are excluded from the analysis.
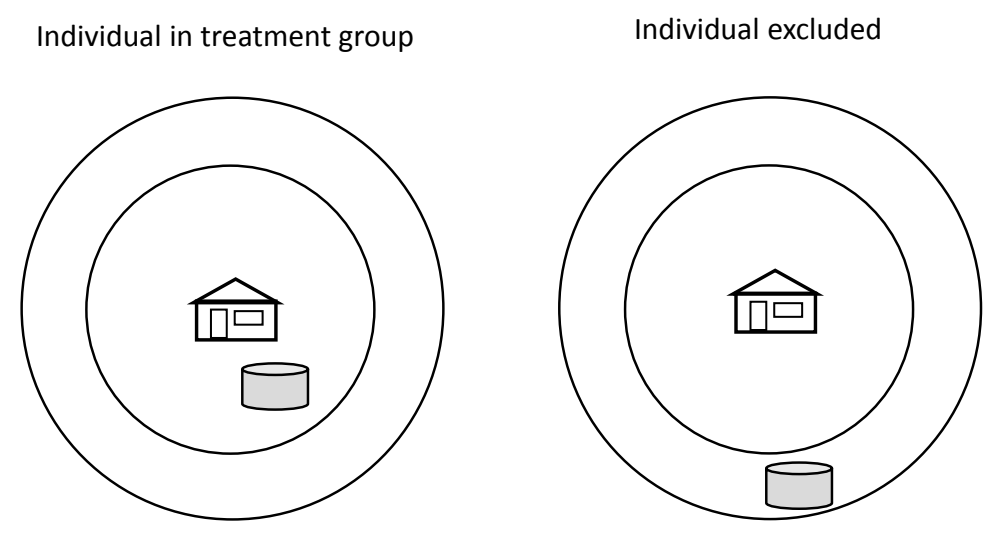

Figure 3: A household, including all its members, is allocated to the treatment group if a biogas plant is operational inside a pre-specified treatment radius in the respective survey year. It is excluded from the analysis if the nearest plant is inside the ban radius.

\subsection{Identification}

To be able to identify the causal effect of a newly built biogas plant on wellbeing we need make two identifying assumptions: ignorability and common trend. Our empirical strategy adopts an intention-to-treat approach, with estimates interpretable as lower bounds.

\footnotetext{
${ }^{14}$ Results are available upon request.

${ }^{15}$ Results are robust to choosing an alternative ban radius of 6,000 metres. Results are available upon request.
} 


\subsubsection{Ignorability}

Ignorability implies that the allocation of households into treatment and control group is independent of the potential outcomes of household members. Threats to ignorability come from within-sample selection, in particular endogenous residential sorting and endogenous construction. ${ }^{16}$

Regarding endogenous residential sorting, individuals with a lower preference for biogas plants might be systematically more likely to live further away from the nearest plant, and vice versa. Such sorting can occur either before or during the observation period. In case it occurs prior, we face preference heterogeneity, and to the extent that preferences are stable, we account for such time-invariant unobserved heterogeneity by routinely including individual fixed effects. In case it occurs during the observation period, however, or in case of endogenous preference formation, we face simultaneity, which we work around by excluding movers from the analysis.

The rationale for focusing on stayers is that the direction of bias resulting from residential sorting is not ex-ante clear. Individuals may move away from biogas plants, switching from the treatment to the control group, if the plant strongly affects them. This moving pattern would bias estimates downward. However, individuals may also move towards plants for reasons unrelated to them, despite having a low preference for plants. Alternatively, they may move towards plants (for example, because biogas plants may reduce rental prices) and mispredict hedonic adaptation to higher disposable income relative to the adaptation to plants (Krekel and Odermatt, 2019). This moving pattern would bias estimates upwards. Other movers may relocate without switching groups: remaining in the treatment group, they may move to a location that is less prone to plant externalities or remain in the control group for entirely unrelated reasons.

\footnotetext{
${ }^{16}$ Individuals might also select out of the sample, which could bias estimates if such out-of-sample selection is correlated with the outcome. To the extent that individuals who are most adversely affected are most likely to drop out, we interpret our estimates as lower bounds.
} 
Yet another type may not realise their move because of a plant at their destination, a counterfactual with welfare implications that is unobservable. Therefore, to arrive at a credible identification of the intention-to-treat-effect, we exclude movers from the analysis.

Regarding endogenous construction, it might be systematically more likely for some households that biogas plants are constructed in their surroundings. This is especially true for farmers: they are more likely to be owners, let land to commercial operators, or generate profits from selling biogas or inputs into biogas production, generating either monetary or non-monetary benefits, or both. The dominance of farmers in the ownership structure of plants is also reflected in siting decisions: most plants are located where biogas in the form of remnant or waste materials is readily available or where energy crops can be cheaply cultivated. We, therefore, exclude all farmers, which make up $1.7 \%$ of individuals, from the analysis (KNI, 2011).

\subsubsection{Common Trend and Matching}

Common trend implies that, in the absence of treatment, treatment and control group would have followed a common trend in outcomes over time. However, the individuals in the treatment group are likely to be considerably different from the individuals in the control group: treated people live close to at least one biogas plant which occurs more frequently in rather rural, agrarian areas, whereas potential control group members come from all parts of the country, including urban areas.

To ensure common trend behaviour, we exclude all households in NUTS-3 regions with a population greater than $500,000 .{ }^{17}$ In a sensitivity analysis, we lower this thresh-

\footnotetext{
${ }^{17}$ As a region, we designate the German administrative areas Landkreise and Kreisfreie Städte. This corresponds to the roughly 400 German NUTS-3 regions. To account for time-varying population sizes, we exclude households if the NUTS-3 region had a population greater than 500,000 in at least one year during the observation period.
} 
old to 100,000 . Our main result remains robust to this lower threshold. ${ }^{18}$ Moreover, we routinely control for a wide range of observables at the individual, household, and NUTS-3 region level, as well as for time-invariant unobserved heterogeneity at the individual level by including individual fixed effects to net out differences between treatment and control group over time. Finally, we apply matching.

We match households in the treatment group with households in the control group based on their geographical locations. This spatial matching is rooted in the first law of geography, stating that objects which are closer to each other are more similar (Tobler, 1970). To operationalise it, we introduce - in addition to the treatment and ban radius - the matching radius: this matching radius goes beyond the ban radius, restricting the control group to households which have the nearest biogas plant within the ring between the ban and the matching radius. A matched household in the control group is unlikely to be exposed to externalities of plants but likely to live in similar spatial conditions as a household in the treatment group. As a default matching radius, we choose 6,000 metres. Beyond this default radius, we carry out sensitivity analyses using larger radii of 9,000 and 12,000 metres. Our main result remains robust to the choice of larger matching radii. ${ }^{19}$ Table B.1 in the Appendix shows balancing properties between treatment group, pre-treatment, and control group: normalised differences are below the threshold of 0.25 for covariate imbalance suggested by Imbens and Wooldridge (2009).

Figure 4 illustrates our spatial matching: all household members on the left are in the treatment group because a biogas plant is present inside the treatment radius; the next household members are excluded because a plant is located inside the ban radius. The members of the third household are part of the control group because a plant is

\footnotetext{
${ }^{18}$ Results are available upon request.

${ }^{19}$ Results are available upon request.
} 
located inside the matching radius (but not inside the treatment or the ban radius). The household members on the right do not enter any group because there is no plant in the vicinity.
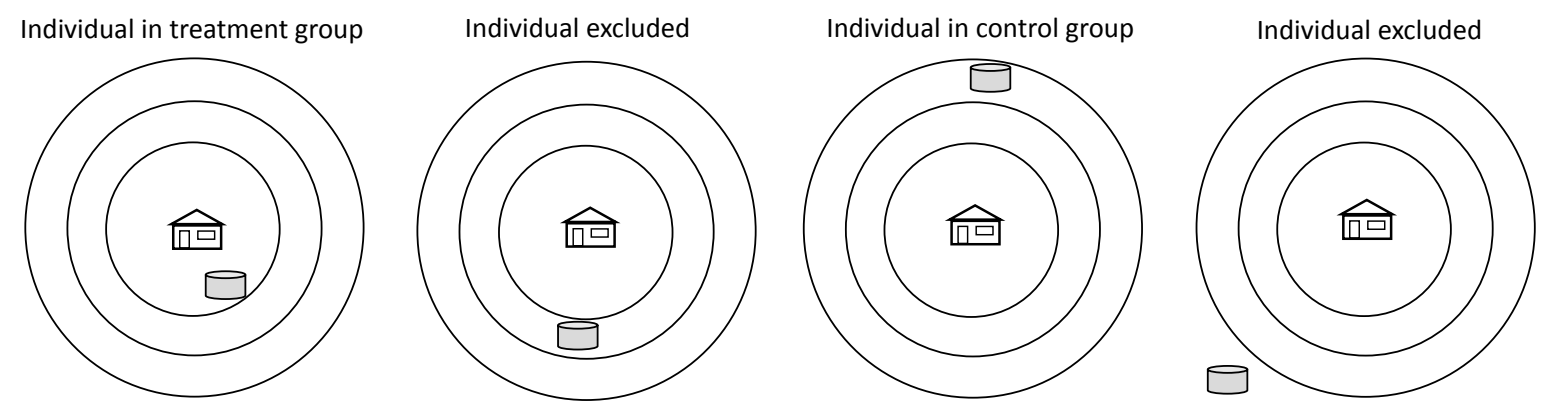

Figure 4: Depending on the distance to the nearest installation, a household is allocated to the treatment group, the control group, or does not enter the analysis.

The following figure plots average life satisfaction, our outcome, covariate-adjusted, for the treatment group, pre-treatment, and the matched control group during the observation period. It shows that both groups exhibit common trend behaviour in pre-treatment life satisfaction over time.

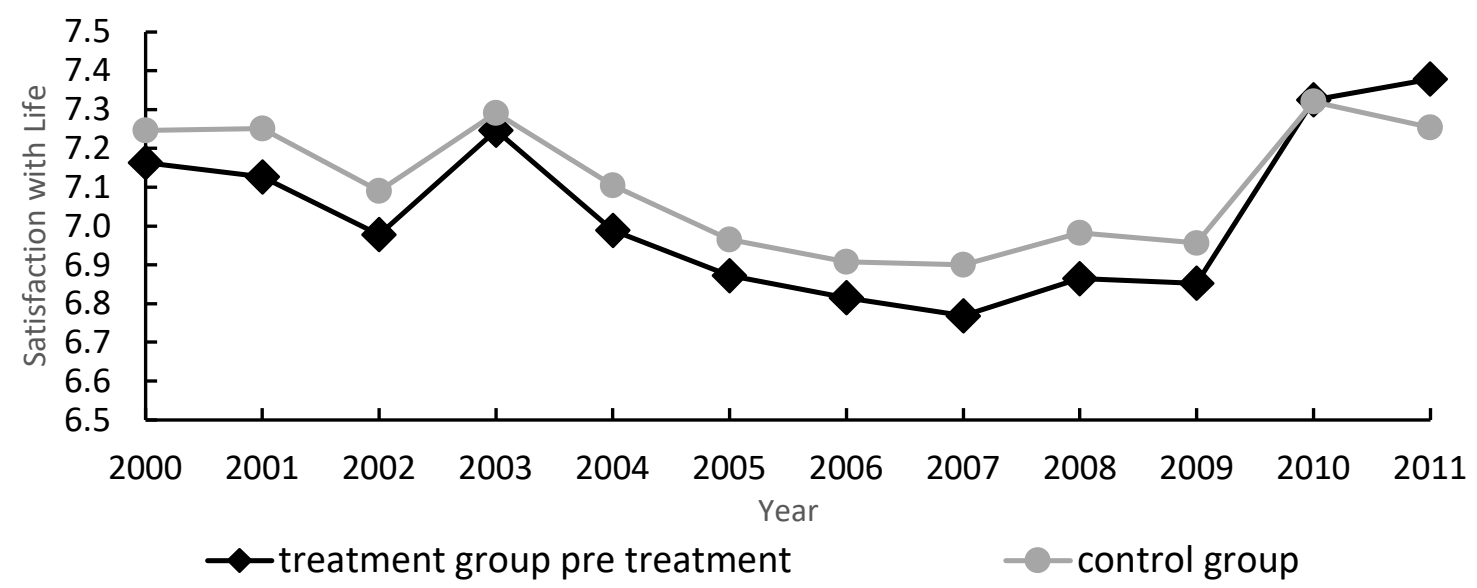

Figure 5: Treatment and control group exhibit common trend behaviour in pre-treatment average life satisfaction over time. 


\subsection{Models}

Our first model, shown in Equation 1, estimates the average treatment effect of a newly constructed biogas plant on subjective wellbeing. treat $_{i t, r}$ is the treatment dummy that equals one if a biogas plant is present inside the treatment radius $r$ around the household of individual $i$ in year $t$, and zero else.

$$
y_{i t}=\beta_{0}+\delta_{\text {treat }} \text { treat }_{i t, r}+X_{i t}^{\prime} \beta_{1}+\gamma_{t}+\mu_{i}+\epsilon_{i t}
$$

$y_{i t}$ is life satisfaction of individual $i$ in year $t . X_{i t}$ is a vector of controls at the individual, household, and NUTS-3 region level, including the log annual net household income and log rental price. ${ }^{20} \gamma_{t}$ are year fixed effects and $\mu_{i}$ captures time-invariant unobserved heterogeneity at the individual level.

Our second model, shown in Equation 2, estimates the treatment effect intensity. Applying this regression, we want to investigate whether household members living downwind of a biogas plant are more affected by the installation compared to those who live upwind.

$$
y_{i t}=\beta_{0}+\delta_{\text {intens1 }} \text { treat }_{i t, r}+\delta_{\text {intens } 2} \text { treat }_{i t, r} \times \text { wind }_{i, \rho}+X_{i t}^{\prime} \beta_{1}+\gamma_{t}+\mu_{i}+\epsilon_{i t}
$$

To decide whether a household is downwind of a certain biogas plant, we construct a cone for each biogas plant. The biogas plant is located at the cone tip; the household lies in the centre of the cone. The angle spans the cone. The variable $w_{i n} d_{i, \rho}$ measures the

\footnotetext{
${ }^{20}$ The SOEP includes two types of rental prices: while renters report actual rents, estimated rents are reported by house owners. The latter is obtained from asking owners to estimate hypothetical rental prices of their houses. We combine both in a single indicator (actual rents for renters, estimated rents for owners).
} 
share of hours in which the wind is blowing from the nearest biogas plant through the cone towards the household during the observation period. wind $_{i, \rho}$ is a (time-invariant) variable which takes on values between zero and one. For instance, a household may be downwind to some biogas plant in a 30 degrees cone in the treatment radius of 1,000 meters for 1,000 hours, on average during our observation period. In this case, its wind intensity is wind $_{i, 30}=0.1142$. We estimate Equation 2 for wind angles $\rho$ of $15,30,45,60,75$, and 90 degrees, respectively

In Figure 6, we illustrate the exposure to wind from a biogas plant. Only in the left panel, the household members are exposed to possible odour emissions because the household lies within cone spanned by $\rho$.
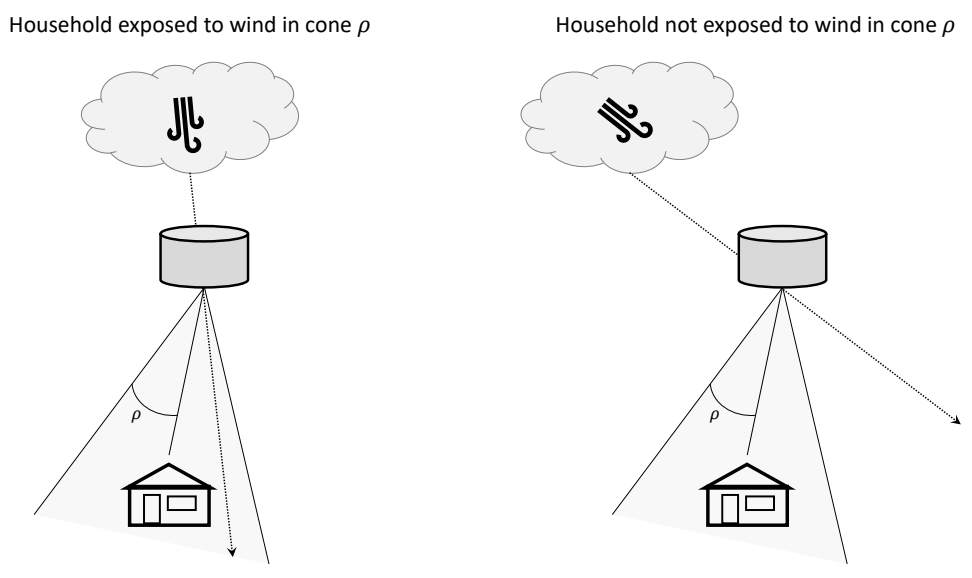

Figure 6: Only if the household, including all its members, lies in cone $\rho$ it is exposed to wind from the biogas plant, see left panel. If the household lies outside of cone $\rho$, it is not exposed to wind from the biogas plant.

Our third model, shown in Equation 3, estimates the treatment effect dynamics: trans $_{i t-\tau, r}$ are dummies that equal one in year $t$, which is $\tau$ years after the first biogas plant appears inside the treatment radius, and zero else. 


$$
y_{i t}=\beta_{0}+\sum_{\tau=1}^{9} \delta_{\tau} \text { trans }_{i t+/-\tau, r}+X_{i t}^{\prime} \beta_{1}+\gamma_{t}+\mu_{i}+\epsilon_{i t}
$$

We estimate all models using fixed-effects (within) estimators. ${ }^{21}$ We show robust standard errors which are clustered at the household level.

\subsection{Interpretation and Limitations}

We cannot be sure whether a household that is allocated to the treatment group is indeed subject to externalities caused by a biogas plant in its surroundings. This has several reasons: first, we proxy externalities caused by biogas plants through treatment radii, which implicitly assumes that externalities decrease in distance to the nearest plant, and are present for any individual at any point in time. This, however, is unlikely to be the case: for example, local weather conditions may greatly reduce externalities. Second, households may adopt mitigating behaviour, for example, by installing air filters, better sealings, or simply opening windows less often. Finally, we only have information on private households: individuals living in places like nursing homes are excluded, and so are temporary visitors such as tourists. We cannot make counterfactual claims about individuals who might have moved and did not do so because of installations. In terms of time use, people spend considerable amounts of time outside their private homes, for example at work, and may thus be less permanently affected. Our identified effects $-\hat{\delta}_{\text {treat }}, \hat{\delta}_{\text {intens } 2}$, and $\hat{\delta}_{\tau}-$ should thus be interpreted as lower-bound, intention-to-treat effects for stayers.

\footnotetext{
${ }^{21}$ Using linear models introduces measurement error as life satisfaction is a discrete, ordinal variable. However, this has become common practice because discrete models for ordinal variables are not applicable to this type of estimator, and bias has been found to be negligible. See, for example, Ferreri-Carbonell and Frijters (2004) for panel data, and Brereton et al. (2008) and Ferreira and Moro (2010) for repeated cross-section data.
} 


\section{Results}

\subsection{Impacts on Life Satisfaction}

Overall Treatment Effect.- Table 6.1 shows the overall treatment effect, which is given by $\hat{\delta}_{\text {treat }}$, estimating Equation 1 forthe treatment radii 1, 000, 1, 500, 2, 000, 2, 500, and 3,000 metres, respectively. The results are sorted from the smallest (left) to the largest treatment radius (right).

Table 6.1: Results: Overall Treatment Effect

Dependent Variable: Satisfaction With Life (Z-Score)

\begin{tabular}{lccccc}
\hline Treatment Radius $r$ in metres & 1,000 & 1,500 & 2,000 & 2,500 & 3,000 \\
\hline treat $_{i t, r}$ & -0.0482 & -0.0516 & $-0.0849^{* *}$ & -0.0475 & -0.0324 \\
& $(0.0519)$ & $(0.0449)$ & $(0.0360)$ & $(0.0318)$ & $(0.0276)$ \\
\hline Controls & Yes & Yes & Yes & Yes & Yes \\
Year Fixed Effects & Yes & Yes & Yes & Yes & Yes \\
Individual Fixed Effects & Yes & Yes & Yes & Yes & Yes \\
\hline Observations & 64,668 & 64,614 & 64,541 & 64,561 & 64,607 \\
Individuals & 14,927 & 14,921 & 14,915 & 14,916 & 14,921 \\
Individuals in Treatment & 645 & 977 & 1,489 & 2,093 & 2,816 \\
Individuals in Control & 14,282 & 13,944 & 13,426 & 12,823 & 12,105 \\
Adjusted $R^{2}$ & 0.1006 & 0.1006 & 0.1005 & 0.1006 & 0.1005 \\
\hline
\end{tabular}

Robust standard errors clustered at household level in parentheses

*** $p<0.01,{ }^{* *} p<0.05,{ }^{*} p<0.1$

Notes: treat $_{i t, r}$ is a dummy that equals one if a biogas plant is present inside treatment radius $r$ around the household of individual $i$ in time period $t$, and zero else. We use a ban radius of 3,000 metres and a matching radius of 6,000 metres. Individuals are allocated to the treatment group if a biogas plant is present inside the treatment radius but not inside the ban radius, and to the control group if a biogas plant is present inside the matching radius but not inside the ban radius (which includes the treatment radius). The control group includes individuals who are allocated to the control group first but may be discarded later, either because a biogas plant with insufficient geographical precision is constructed inside the treatment radius or a biogas plant (regardless of geographical precision) is constructed inside the ban radius during the observation period. The outcome is life satisfaction, which has been standardised to have mean zero and standard deviation one. The controls include, among others, the $\log$ annual net household income and rental prices (actual rents for renters, estimated rents for owners). See Equation 1 for the model. All numbers are rounded to four decimal places.

Source: SOEP (2015), 2000-2012, individuals aged 17 or older, and data on biogas plants described in Section 4.2, own calculations 
Our estimated coefficients are consistently negative. They increase in size when moving from the 1,000 to the 2,000 metres treatment radius, from about -0.05 ( $5 \%$ of a standard deviation) to $-0.08(8 \%)$. Beyond the 2,000 metres radius, effect sizes decrease in size. Standard errors decrease the more one is moving away from the nearest biogas plant (as the size of the treatment group increases from 645 in the 1, 000 metres to 2,816 in the 3,000 metres radius). Only the coefficient for the 2,000 metres treatment radius reaches significance at the $5 \%$ level.

As expected, for the pattern of coefficients beyond the 2,000 metres treatment radius, the overall treatment effect decreases with distance, in line with a standard doseresponse interpretation. However, for the pattern of coefficients below the 2, 000 metres radius, effect sizes are smaller, steadily increasing from the 1,000 to the 2,000 metres radius. Impacts on life satisfaction in our sample are thus U-shaped regarding the distance to the nearest installation. While the loss of power can explain insignificant impacts at lower distances, it cannot explain this U-shaped pattern. ${ }^{22}$

There may be several forces at play which might explain the U-shaped pattern: first, there may be a genuinely non-linear dose-response relationship. This is rather unlikely, though: the nature of biogas plant externalities (in particular odour emissions) suggests that impacts should be, on average, stronger at lower distances. More likely, it may be that the treatment group at lower distances includes - besides individuals who are genuinely negatively affected - individuals who may benefit from the plant, either monetarily or non-monetarily, for example by selling electricity or heat to nearby households or by receiving (targeted) compensations by plant operators (which are not legally mandated but often occur in practice). Although we focus on private households

\footnotetext{
${ }^{22}$ The treatment group in the 1,000 metres treatment radius is less than half the size of that in the 2, 000 metres radius, yielding, on average, 50 as opposed to 114 individuals in the treatment group per year.
} 
and exclude farmers (who are more likely to either build plants themselves or lease land to utilities which then build them), we cannot exclude this case with certainty. Related, individuals who are most adversely affected (who are likely to live closer to the nearest plant) might move away, crowding out the treatment group, which consists of stayers. The significant, negative effect for the 2,000 metres treatment radius may then result from the interplay of these forces: as the externality decreases with distance, the relative share of individuals in the treatment group who are genuinely negatively affected goes up, up to a point at which a significant, negative effect can be detected. The detected effect for the 2,000 metres treatment radius is then in line with a lowerbound interpretation.

This U-shaped pattern is persistent, sustaining sensitivity analyses that redefine treatment and control group based on different ban and matching radii, different requirements regarding data quality of biogas plants, and different operationalisations of restricting the sample to rural areas, depending on definition. ${ }^{23}$ When ex-ante excluding individuals from the control group who would have otherwise been discarded later during the observation period (either because a plant is constructed inside the ban radius or because a plant with insufficient geographical precision is constructed in their surroundings), we obtain the same pattern, with attenuated effect sizes (Appendix Table C.1). This is somewhat expected, as ex-ante excluding these individuals is akin to excluding those individuals who are most comparable to the treatment group.

Treatment Effect Intensity.- We analyse the treatment effect intensity, by estimating Equation 2. The coefficient of interest, $\delta_{\text {intens } 2}$, captures the effect of the interaction term of the treatment dummy treat $t_{i t, r}$ and the (time-invariant) parameter $w_{i n d} d_{i, \rho}$

Table C.2 in the Appendix shows the estimated treatment effect intensity for the 2,000 metres treatment radius, which is our main finding in the previous analysis.

\footnotetext{
${ }^{23}$ Results are available upon request.
} 
We find that treatment effect intensity is consistently negative but does not reach significance. Moving from a cone spanning $2 \times 15=30$ to one spanning $2 \times 90=180$ degrees, we find an intuitive pattern, though: treatment effect intensity appears to be increasing in wind intensity for households located downwind from the nearest biogas plant, pointing towards odour emissions as a prime externality. Recall that the smaller the opening of the cone, as indicated by a lower wind angle $\rho$, the less frequent is a household affected by wind but, the higher is the actual average wind intensity (because the wind is less likely to miss the household in a smaller cone).

Note that the sample size in this analysis drops substantially, as only a subset of the individuals in our original treatment group (that is, those who are located in the cone downwind from the nearest installation) are included. Insignificant impacts may thus be the result of a loss of power.

Treatment Effect Dynamics.- We next look at treatment effect dynamics, by interacting the treatment dummy treat $_{i t, r}$ with dummies trans $_{i t-\tau, r}$ that equal one in year $t$, which is $\tau$ years after the first biogas plant is constructed inside the treatment radius, and zero else. As our power again drops substantially for part of this analysis, results are only exploratory.

Table C.3 in the Appendix shows the estimated treatment effect dynamics, again for the 2,000 metres treatment radius. We find that dummies for post-construction periods are consistently negative, whereas those for pre-construction periods (except the first lead) are consistently positive. Yet, most do not reach significance, with two exceptions. The first is a relatively strong, significant positive effect of the second lead, the second a strong, significant negative effect of the sixth lag. The positive effect of the second lead is persistent, sustaining several re-definitions of treatment and control group based on, for example, different treatment, ban, or matching radii. We can only speculate about its causes here, which may include upfront compensation measures to 
households located close to planned new build projects. These are not legally mandated but do occur in practice.

Overall, when it comes to the adaptation of individuals to the presence of installations in their surroundings, our findings here remain inconclusive: while consistently negative coefficients for post-construction periods point towards sustained negative impacts, we cannot reject the null that these impacts are in fact zero. Indeed, the farther we move away from the year of construction, the more observations we lose. Insignificant impacts may thus be the result of a loss of power.

\subsection{Impacts on Alternative Outcomes}

Finally, we replace our main outcome - satisfaction with life - with two alternative outcomes: worries about crime and worries about health, both of which are obtained from a battery of three-point Likert scale questions asking respondents: "What is your attitude towards the following areas - are you concerned about them?" Choices include, amongst others: "Your Health" and "Crime in Germany". Answer possibilities are "Very", "Somewhat", and "Not at all". We dichotomise these variables so that one indicates whether a respondent is very or somewhat worried about the respective area, and zero else. We exploit worries about crime as a placebo (we do not expect biogas plant construction to have any impact on this outcome) and worries about health as an exploratory outcome into the mechanisms through which negative impacts of biogas plants on life satisfaction may manifest themselves. 
Table 6.2: Results: Impacts Alternative Outcomes (Z-Scores)

Treatment Radius: 2,000 metres

\begin{tabular}{lcc}
\hline Alternative Outcome & Worries About Crime (Placebo) & Worries About Health \\
\hline treat ${ }_{i t, r}$ & -0.0113 & $0.0388^{* * *}$ \\
& -0.0113 & $(0.0143)$ \\
\hline Controls & Yes & Yes \\
Year Fixed Effects & Yes & Yes \\
Individual Fixed Effects & Yes & Yes \\
\hline Observations & 51,477 & 51,479 \\
Individuals & 11,953 & 11,951 \\
Individuals in Treatment & 1,330 & 1,331 \\
Individuals in Control & 10,623 & 10,620 \\
Adjusted $R^{2}$ & 0.0321 & 0.1428 \\
\hline \multicolumn{2}{c}{ Robust standard errors clustered at household level in parentheses } \\
$* * *$ & $p<0.01,{ }^{* *} p<0.05,{ }^{*} p<0.1$ &
\end{tabular}

Notes: treat $_{i t, r}$ is a dummy that equals one if a biogas plant is present inside treatment radius $r$ around the household of individual $i$ in time period $t$, and zero else. We use a ban radius of 3,000 metres and a matching radius of 6,000 metres. Individuals are allocated to the treatment group if a biogas plant is present inside the treatment radius but not inside the ban radius, and to the control group if a biogas plant is present inside the matching radius but not inside the ban radius (which includes the treatment radius). The control group includes individuals who may be allocated to the control group first but may be discarded later, either because a biogas plant with insufficient geographical precision is constructed inside the treatment radius or a biogas plant (regardless of geographical precision) is constructed inside the ban radius, during the observation period. The alternative outcomes are worries about crime and worries about health, all of which have been standardised to have mean zero and standard deviation one. The controls include, among others, the log annual net household income and rental prices (actual rents for renters, estimated rents for owners). See Equation 1 for the model. All numbers are rounded to four decimal places. Source: SOEP (2015), 2000-2012, individuals aged 17 or older, and data on biogas plants described in Section 4.2, own calculations

Table 6.2 replicates Table 6.1 for our two alternative outcomes, again for the 2, 000 metres treatment radius. As expected, we find that the construction of a biogas plant does not have any impact on worries about crime. However, it increases the likelihood that respondents are worried about their health by about four percentage points. This may point towards presumed negative impacts of biogas plants on the health of nearby residents as a potential mechanism through which impacts on more global, evaluative measures of wellbeing come about. 
To check this more formally, Table C.4 and Table C.5 in the Appendix replicates

Table 6.1 for physical and mental health outcomes, respectively, obtained from the Short-Form (SF12) Health Survey: we are unable to detect any health impacts, neither on physical nor mental health, on average or for different sub-components, suggesting that the negative wellbeing impacts identified in our main model are not driven by negative health impacts.

\section{Discussion and Conclusion}

Stated-preferences approaches, which directly ask respondents about their preferences towards renewables, find that biogas is by far the most unpopular renewable (Andor et al., 2015). Only 51\% of respondents living close to a plant report to be supportive of the technology, compared to, for example, $72 \%$ in case of wind turbines (Meyerhoff et al., 2015). Most report a minimum setback distance between three and eight kilometres as acceptable, citing perceived odour emissions as the primary source of nuisance (Schumacher and Schultmann, 2017). Likewise, revealed-preferences approaches, which use changes in real estate prices to elicit preferences, find that biogas plants are associated with reduced house prices in their surroundings.

While revealed-preferences approaches may be difficult to implement in rural areas where biogas plants are typically located (simply because there are not many housing transactions observable), stated-preferences approaches may yield biased estimates if respondents have incentives to answer in a strategic way, which may be the case if they are expressing their attitudes towards an existing or planned installation in their surroundings - often the objective of surveys looking at the acceptance of new build projects. We overcome some of these issues by looking at experienced preferences, and in particular, the self-reported life satisfaction of individuals in households close to 
biogas plants. In this approach, the relationship between respondents' self-reports and installations in their surroundings remains covert.

We use the universe of biogas plants constructed in Germany during the 2000 to 2012 period (more than 13,000 installations) and a spatial difference-in-differences design that exploits exact geographical coordinates of households and installations. We find limited evidence on negative externalities of biogas plants, partly confirming results from previous studies using stated and revealed preferences. In particular, we find that the construction of a biogas plant inside a 2,000 metres radius around households has a significant, negative effect on the self-reported life satisfaction of household members, holding everything else (including real estate prices) constant. However, when comparing overall treatment effects of biogas plants to those of wind turbines obtained using the same methodology, impacts turn out to be smaller (about $8 \%$ of a standard deviation versus $11 \%$ ) and much more spatially confined (detectable up to 2,000 metres versus 4,000 metres) (Krekel and Zerrahn, 2017). As with wind turbines, impacts are likely to be lower bounds: our research design focuses on respondents interviewed in private households while deliberately excluding individuals who move (either between treatment and control group, or within either group) during the observation period. If such moving is in any way related to the construction of biogas plants in their surroundings, these individuals are arguably the most adversely affected.

We compare our estimates to the literature: von Möllendorff and Welsch (2017) find that having at least one biogas plant in the post-code area of households reduces the self-reported life satisfaction of household members by about $2 \%$ of a standard deviation. This is about a quarter of the size of the effect we identify. As we are able to identify this (stronger) effect for a maximum treatment radius of 2,000 metres around plants only, our results and those of von Möllendorff and Welsch seem to be in line. 
Our exploratory analysis of treatment effect intensity remains inconclusive: although effect sizes point towards stronger impacts for individuals in households located downwind from the nearest biogas plant, coefficients do not reach significance. Likewise, an exploratory analysis of treatment effect dynamics remains inconclusive: while coefficients have positive signs in pre-construction and negative signs in post-construction periods, coefficients do not, with few exceptions, reach significance. In both analyses, sample size drops to about half. Insignificant impacts may thus result from a loss of power.

Applying the precautionary principle, our findings suggest a minimum setback distance of about 2,000 metres (possibly with a margin, depending on plant characteristics) between biogas plants and neighbouring residential areas. This is lower than the minimum setback distance typically found in stated-preference approaches but more than is often implemented in practice. Recall that there exists no legal mandate for a uniform minimum setback distance across German federal states and regions but that distances are decided upon on a case-by-case basis, depending on plant and area characteristics. These can fall well below 1,000 metres. The Biogas Handbook for Bavaria (Biogashandbuch Bayern), for example, specifies minimum setback distances between 300 and 500 metres for open and closed installations.

If households fall below this 2, 000 metres minimum setback distance, possible strategies include eliminating the negative externality to the extent possible (with incurred costs ideally borne by plant owners), or compensating affected households either monetarily or non-monetarily for their welfare loss. To arrive at a possible range of compensations, we can provide a cautionary, back-of-the-envelope calculation of the implicit willingness-to-pay of individuals to avoid a biogas plant inside a 2,000 metres radius around their households. 
We next calculate the willingness-to-pay for plant avoidance. Applying again the precautionary principle, we assume that there is no hedonic adaptation to biogas plants. Recall that the construction of a new installation inside a 2,000 metres radius around households reduces the self-reported life satisfaction of household members by about $8 \%$ of a standard deviation or, given a standard deviation of life satisfaction of about 1.8, by about 0.14 points on a zero-to-ten scale. We take an established income coefficient from the literature: Stevenson and Wolfers (2008) obtain an estimate of about 0.35 for a level-log specification in which life satisfaction (standardised) is regressed on annual net household income, which is about $0.35 \times 1.8=0.63$ in natural units. A $1 \%$ increase in annual net household income, therefore, raises life satisfaction by about $0.63 \div 100=$ 0.0063 points. The mean annual net household income in our estimation sample is about 31,000 EUR (36, 480 USD). The implicit willingness-to-pay to avoid a biogas plant inside a 2, 000 metres radius around their households is, therefore, ((31,000 EUR $\times$ $1 \%) \times(0.14)) \div 0.0063 \approx 6,900$ EUR $(8,120$ USD) per individual per year or 575 EUR (677 USD) per individual per month. ${ }^{24}$ As there are, on average, 3.1 individuals per household in our estimation sample, this yields 1, 783 EUR (2, 098 USD) per household per month.

Note, however, that such implicit willingness-to-pay calculations based on wellbeing data are very sensitive to the choice of the income coefficient estimate, which varies widely in the literature. An income coefficient estimate of 0.68 is rather large (although by no means the largest ever found). ${ }^{25}$ A smaller estimate would inflate the calculated implicit willingness-to-pay substantially, simply because the income coefficient is the divisor in the monetisation formula. For example, an estimate of around 0.2 or below,

\footnotetext{
${ }^{24}$ Using an exchange rate of $1: 1.18$ as of July $29,2020$.

${ }^{25}$ Kahneman and Deaton (2010) report an estimate of 0.64 using Gallup Healthways, Deaton (2008) of 0.84 using Gallup World Poll data, and Pischke (2011) of 0.78 using the SOEP, i.e. the same household panel as the present study.
} 
which is found in panel data settings, would inflate its value by three times or more the original size. Potential reasons for these differences in income coefficient estimates are the definition of income, the source of exogenous variation (or the lack thereof), measurement error, different estimation techniques, and behavioural reasons such as adaptation, anticipation, or simply the non-visibility of relatively small income changes which may downward bias their impacts on wellbeing. A relatively large income coefficient estimate is therefore, arguably, a conservative approach to monetisation.

Whatever the approach to their monetisation, there is evidence that biogas plants have negative external effects on their surroundings. Local resistance can thus not be neglected. Their strong spatial limitation, however, suggests that these effects can, in practice, be mitigated relatively easy. Such mitigation measures, including setback distances and involving local residents in procedures concerning siting and construction, are possibly the way forward to enhance the deployment of the technology. 


\section{References}

Adler, M. D., P. Dolan, and G. Kavetsos (2017). Would you choose to be happy? Tradeoffs between happiness and the other dimensions of life in a large population survey. Journal of Economic Behavior \& Organization 139, 60-73.

Administrative Court Munich (2016). Judging of 26/07/2016: 2 B 15.2392. https: //dejure.org/dienste/vernetzung/rechtsprechung?Text=2\%20B\%2015. 2392.

Ambrey, C., C. Fleming, and A.-C. Chan (2014). Estimating the cost of air pollution in South East Queensland: An application of the life satisfaction non-market valuation approach. Ecological Economics 97, 172-181.

Andor, M., M. Frondel, and S. Rinne (2015). Wie unbeliebt ist Kohle und wie beliebt sind die Erneuerbaren? Eine empirische Regionalanalyse der energiepolitischen Präferenzen deutscher Haushalte. RWI Diskussionspapier 93.

Bavarian State Office for the Environment (BSOE) (2011). Biogashandbuch Bayern. https://www.lfu.bayern.de/energie/biogashandbuch/index.htm.

Becker, G. and L. Rayo (2008). Economic growth and subjective well-being: Reassessing the Easterlin Paradox'. Comments and discussion. Brookings Papers on Economic Activity 39(1), 88-102.

Benjamin, D., O. Heffetz, M. Kimball, and A. Rees-Jones (2012). What do you think would make you happier? What do you think you would choose? American Economic Review 102(5), 2083-2110.

Bertram, C., J. Goebel, C. Krekel, and K. Rehdanz (2020). Urban land use fragmentation and human wellbeing. Kiel Working Paper $214 \%$. 
Bertram, C. and K. Rehdanz (2015). The role of urban green space for human wellbeing. Ecological Economics 120, 139-152.

Bertsch, V., M. Hall, C. Weinhardt, and W. Fichtner (2016). Public acceptance and preferences related to renewable energy and grid expansion policy: empirical insights for Germany. Energy 114, 465-477.

Brereton, F., J. Clinch, and S. Ferreira (2008). Happiness, geography and the environment. Ecological Economics 65(2), 386-396.

Bundesministerium für Wirtschaft und Energie (BMWi) (2017). Zeitreihen zur Entwicklung der erneuerbaren Energien in Deutschland. http: //www. erneuerbare-energien.de/EE/Navigation/DE/Service/Erneuerbare_ Energien_in_Zahlen/Zeitreihen/zeitreihen.html.

Bundesministerium für Wirtschaft und Energie (BMWi) (2020). Zeitreihen zur Entwicklung der erneuerbaren Energien in Deutschland. http: //www. erneuerbare-energien.de/EE/Navigation/DE/Service/Erneuerbare_ Energien_in_Zahlen/Zeitreihen/zeitreihen.html.

Deaton, A. (2008). Income, health, and well-being around the world: Evidence from the gallup world poll. Journal of Economic Perspectives 22(2), 53-72.

Diener, E., E. Suh, R. Lucas, and H. Smith (1999). Subjective well-being: Three decades of progress. Psychological Bulletin 125(2), 276-302.

Dobers, G. M. (2019). Acceptance of biogas plants taking into account space and place. Energy Policy 135, 110987.

Dolan, P., G. Kavetsos, C. Krekel, D. Mavridis, R. Metcalfe, C. Senik, S. Szymanski, 
and N. Ziebarth (2019). Quantifying the intangible impact of the Olympics using subjective well-being data.

Ferreira, S., A. Akay, F. Brereton, J. Cuñado, P. Martinsson, and M. Moro (2013). Life satisfaction and air quality in Europe. Ecological Economics 88, 1-10.

Ferreira, S. and M. Moro (2010). On the use of subjective well-being data for environmental valuation. Environmental and Resource Economics 46(3), 249-273.

Ferrer-i-Carbonell, A. and P. Frijters (2004). How important is methodology for the estimates of the determinants of happiness? Economic Journal 114(497), 641-659.

Gelaro, R., W. McCarty, M. J. Suárez, R. Todling, A. Molod, L. Takacs, C. A. Randles, A. Darmenov, M. G. Bosilovich, R. Reichle, K. Wargan, L. Coy, R. Cullather, C. Draper, S. Akella, V. Buchard, A. Conaty, A. M. da Silva, W. Gu, G.-K. Kim, R. Koster, R. Lucchesi, D. Merkova, J. E. Nielsen, G. Partyka, S. Pawson, W. Putman, M. Rienecker, S. D. Schubert, M. Sienkiewicz, and B. Zhao (2017). The modernera retrospective analysis for research and applications, version 2 (merra-2). 30(14), $5419-5454$.

Glaeser, E., J. Gottlieb, and O. Ziv (2016). Unhappy cities. Journal of Labor Economics 34 (S2), S124-S182.

Global Modeling and Assimilation Office (GMAO) (2015). MERRA-2 tavg1_2d_slv_Nx: 2d,1-Hourly,Time-Averaged,Single-Level,Assimilation,Single-Level Diagnostics V5.12.4. https://doi.org/10.5067/VJAFPLI1CSIV.

Goebel, J. and B. Pauer (2014). Datenschutzkonzept zur Nutzung von SOEPgeo im Forschungsdatenzentrum SOEP am DIW Berlin. Zeitschrift für amtliche Statistik Berlin-Brandenburg 3, 42-47. 
Groß-Gerau Online (2018). Biokraftwerk / Biogaswerk in Groß-Gerau/Wallerstädten. http://www.gg-online.de/html/biokraftwerk.htm.

Imbens, G. W. and J. M. Wooldridge (2009). Recent developments in the econometrics of program evaluation. Journal of Economic Literature 47(1), 5-86.

International Energy Agency (IEA) (2020). Renewables information overview 2020. https://webstore.iea.org/download/direct/4030?fileName=Renewables_ Information_Overview_2020_edition.pdf.

International Renewable Energy Agency (IRENA) (2020). Renewable energy statistics 2020. http://www.irena.org/-/media/Files/IRENA/Agency/Publication/2020/ Jul/IRENA_Renewable_Energy_Statistics_2020.pdf.

Kahneman, D. and A. Deaton (2010). High income improves evaluation of life but not emotional well-being. Proceedings of the National Academy of Sciences 107(38), $16489-16493$.

Kahneman, D. and R. Sugden (2005). Experienced utility as a standard of policy evaluation. Environmental $\&$ Resource Economics 32(1), 161-181.

Kahneman, D., P. Wakker, and R. Sarin (1997). Back to bentham? Explorations of experienced utility. Quarterly Journal of Economics 112(2), 375-406.

Keles, D., J. Choumert, P. Combes-Motel, and Éric N. Kéré (2017). Does the expansion of biofuels encroach on the forest? Document de Travail du Laboratoire d'Economie Forestière 2017-09.

Klaus Novy Institute (KNI) and trend:research (2011). Marktakteure Erneuerbare-Energien-Anlagen in der Stromerzeugung. http: 
//www.forschungsradar.de/studiendatenbank/studie/detail/ marktakteure-erneuerbare-energien-anlagenin-der-stromerzeugung.html.

Kopmann, A. and K. Rehdanz (2013). A human well-being approach for assessing the value of natural land areas. Ecological Economics 93, 20-33.

Krekel, C., J. Kolbe, and H. Wüstemann (2016). The greener, the happier? The effect of urban land use on residential well-being. Ecological Economics 121, 117-127.

Krekel, C. and R. Odermatt (2019). Behavioural spatial economics: Utility misprediction in locational choices and spatial sorting.

Krekel, C. and A. Zerrahn (2017). Does the presence of wind turbines have negative externalities for people in their surroundings? Evidence from well-being data. Journal of Environmental Economics and Management 82, 221-238.

Levinson, A. (2012). Valuing public goods using happiness data: The case of air quality. Journal of Public Economics 96(9-10), 869-880.

Luechinger, S. and P. Raschky (2009). Valuing flood disasters using the life satisfaction approach. Journal of Public Economics 93(3-4), 620-633.

Meyerhoff, J., V. Hartje, and M. Oehlmann (2015). Effiziente und gerechte Allokation der Produktion erneuerbarer Energien auf nationaler Ebene. Studie im Rahmen des Forschungsprojekts EnergyEFFAIR. https://www.landschaftsoekonomie. tu-berlin.de/fileadmin/a0731/uploads/personen/meyerhoff/ EnergyEFFAIR-BMBF-Klimaoekonomie-Ergebnisbroschuere-Nov2015 pdf.

Modica, M. (2017). Does the construction of biogas plants affect local property values? Economics Letters 159, 169-172. 
Pechrova, M. and V. Lohr (2016). Valuation of the externalities from biogas stations. In Conference: Mathematical Methods in Economics, Volume 34.

PEW Research Center (2016). The politics of climate - 2. Public opinion on renewables and other energy sources. https://www. pewresearch.org/science/2016/10/04/ public-opinion-on-renewables-and-other-energy-sources/.

Pischke, J.-S. (2011). Money and happiness: Evidence from the industry wage structure. CEP Discussion Paper.

Rehdanz, K. and D. Maddison (2008). Local environmental quality and life-satisfaction in Germany. Ecological Economics 64(4), 787-797.

Schumacher, K. and F. Schultmann (2017). Local acceptance of biogas plants: A comparative study in the trinational Upper Rhine region. Waste and Biomass Valorization 8(7), 2393-2412.

SOEP (2015). German Socio-Economic Panel Study: Data for Years 1984-2015, Version 32. doi: 10.5684/soep.v32.

Soland, M., N. Steimer, and G. Walter (2013). Local acceptance of existing biogas plants in Switzerland. Energy Policy 61, 802-810.

Stevenson, B. and J. Wolfers (2008). Economic growth and subjective well-being: Reassessing the Easterlin paradox. Brookings Papers on Economic Activity 1(39), 1102.

Tobler, W. (1970). A computer movie simulating urban growth in the Detroit region. Economic Geography 46(Supplement), 234-240.

Umweltbundesamt (2019). Umweltbewusstsein in Deutschland 2018 - Ergebnisse einer repräsentativen Bevölkerungsumfrage. https://www.umweltbundesamt. 
de/sites/default/files/medien/1410/publikationen/ubs2018_-_m_3.3_ basisdatenbroschuere_barrierefrei-02_cps_bf.pdf.

Upham, P. (2009). Applying environmental-behaviour concepts to renewable energy siting controversy. Reflections on a longitudinal bioenergy case study. Energy Policy $37(11), 4273-4283$.

Upham, P. and S. Shackley (2006). The case of a proposed 21.5 MWe biomass gasifier in Winkleigh, Devon. Implications for governance of renewable energy planning. Energy Policy $34(15), 2161-2172$.

Upham, P. and S. Shackley (2007). Local public opinion of a proposed 21.5 MW(e) biomass gasifier in Devon. Questionnaire survey results. Biomass and Bioenergy $31(6), 433-441$.

Upreti, B. (2004). Conflict over biomass energy development in the United Kingdom: some observations and lessons from England and Wales. Energy Policy 32(6), 785800.

Upreti, B. and D. van der Horst (2004). National renewable energy policy and local opposition in the UK: the failed development of a biomass electricity plant. Biomass and Bioenergy 26(1), 61-69.

van Praag, B. and B. Baarsma (2005). Using happiness surveys to value intangibles: The case of airport noise. Economic Journal 115(500), 224-246.

von Möllendorff, C. and H. Welsch (2017). Measuring renewable energy externalities: Evidence from subjective well-being data. Land Economics 93(1), 109-126.

Wagner, G., J. Frick, and J. Schupp (2007). The German Socio-Economic Panel Study 
(SOEP) - Scope, evolution, and enhancements. Schmollers Jahrbuch 127(1), 139169.

Wagner, G., J. Goebel, P. Krause, R. Pischner, and I. Sieber (2008). Das SozioOekonomische Panel (SOEP): Multidisziplinäres Haushaltspanel und Kohortenstudie fuer Deutschland - Eine Einführung (für neue Datennutzer) mit einem Ausblick (für erfahrene Anwender). AStA Wirtschafts- und Sozialstatistisches Archiv 2(4), 301328.

Welsch, H. and S. Ferreira (2014). Environment, well-being, and experienced preference. International Review of Environmental and Resource Economics 7(3-4), 205-239.

Welsch, H. and J. Kühling (2009). Using happiness data for environmental valuation: Issues and applications. Journal of Economic Surveys 23(2), 385-406.

Wüste, A. and P. Schmuck (2013). Sustainable bioenergy production - an integrated approach. In H. Ruppert, M. Kappas, and J. Ibendorf (Eds.), Social acceptance of bioenergy use and the success factors of communal bioenergy projects, pp. 293-318. Berlin: Springer.

Zemo, K. H., T. E. Panduro, and M. Termansen (2019). Impact of biogas plants on rural residential property values and implications for local acceptance. Energy Policy 129, $1121-1131$.

Zoellner, J., P. Schweizer-Ries, and C. Wemheuer (2008). Public acceptance of renewable energies: Results from case studies in Germany. Energy Policy 36, 4136-4141.

Überlandwerk Groß-Gerau GmbH (2018). Biogasanlage Wallerstädten. http://www . uewg.de/privatkunden/energiewende/referenzprojekte/biogasanlage.html. 


\title{
Appendix A. Data
}

\author{
Appendix A.1. Household Data
}

Table A.1: Summary Statistics for Household Data

\begin{tabular}{|c|c|c|c|c|c|}
\hline Variables & Mean & Stand. Deviation & Minimum & Maximum & \# Observations \\
\hline \multicolumn{6}{|l|}{ Outcome } \\
\hline Life Satisfaction & 7.0907 & 1.7531 & 0 & 10 & 64,541 \\
\hline \multicolumn{6}{|l|}{ Controls } \\
\hline Age & 53.2636 & 16.3363 & 16 & 100 & 64,541 \\
\hline Is Married & 0.7207 & 0.4487 & 0 & 1 & 64,541 \\
\hline Is Divorced & 0.0590 & 0.2356 & 0 & 1 & 64,541 \\
\hline Is Widowed & 0.0741 & 0.2619 & 0 & 1 & 64,541 \\
\hline Has Very Good Health & 0.0774 & 0.2672 & 0 & 1 & 64,541 \\
\hline Has Good Health & 0.3726 & 0.4835 & 0 & 1 & 64,541 \\
\hline Has Bad Health & 0.1502 & 0.3573 & 0 & 1 & 64,541 \\
\hline Has Very Bad Health & 0.0411 & 0.1984 & 0 & 1 & 64,541 \\
\hline Is Disabled & 0.1372 & 0.3440 & 0 & 1 & 64,541 \\
\hline Is in School & 0.0151 & 0.1219 & 0 & 1 & 64,541 \\
\hline Has Lower Than Secondary Degree & 0.1535 & 0.3604 & 0 & 1 & 64,541 \\
\hline Has Tertiary Degree & 0.2702 & 0.4441 & 0 & 1 & 64,541 \\
\hline Is in Training & 0.0157 & 0.1242 & 0 & 1 & 64,541 \\
\hline Is Part-Time Employed & 0.1132 & 0.3169 & 0 & 1 & 64,541 \\
\hline Is Irregularly Employed & 0.0462 & 0.2099 & 0 & 1 & 64,541 \\
\hline Is on Parental Leave & 0.0113 & 0.1057 & 0 & 1 & 64,541 \\
\hline Is Unemployed & 0.0414 & 0.1993 & 0 & 1 & 64,541 \\
\hline Is Out of Labour Force & 0.4773 & 0.4995 & 0 & 1 & 64,541 \\
\hline Log Mean Annual Net Household Income & 10.396 & 0.6062 & 3.6889 & 13.6141 & 64,541 \\
\hline Number of Children in Household & 1.7312 & 0.4433 & 1 & 2 & 64,541 \\
\hline Number of Rooms Per Individual & 1.8710 & 0.9603 & 0.2500 & 15.0000 & 64,541 \\
\hline Lives in Small Apartment Building & 0.1886 & 0.3912 & 0 & 1 & 64,541 \\
\hline Lives in Medium-Sized Apartment Building & 0.0909 & 0.2875 & 0 & 1 & 64,541 \\
\hline Lives in Large Apartment Building & 0.1482 & 0.3553 & 0 & 1 & 64,541 \\
\hline Lives in High Rise & 0.0995 & 0.2994 & 0 & 1 & 64,541 \\
\hline Local Unemployment Rate in Percent & 9.0858 & 4.6746 & 1.2000 & 25.4000 & 64,541 \\
\hline Log Mean Local Household Income ${ }^{\mathrm{a}}$ & 7.2840 & 0.1573 & 6.8704 & 8.1791 & 64,541 \\
\hline Log Mean Annual Rental Price of Dwelling & 8.8897 & 0.5465 & 5.2575 & 11.6952 & 64,541 \\
\hline
\end{tabular}

Source: SOEP (2015), 2000-2012, individuals aged 17 or older, own calculations 
Appendix A.2. Data on Biogas Plants

Table A.2: Number of New Built Biogas Plants by Year

\begin{tabular}{cc}
\hline Year & Number \\
\hline 1978 & 1 \\
1979 & 0 \\
1980 & 0 \\
1981 & 0 \\
1982 & 0 \\
1983 & 0 \\
1984 & 1 \\
1985 & 0 \\
1986 & 1 \\
1987 & 2 \\
1988 & 3 \\
1989 & 1 \\
1990 & 1 \\
1991 & 3 \\
1992 & 1 \\
1993 & 5 \\
1994 & 25 \\
1995 & 27 \\
1996 & 42 \\
1997 & 35 \\
1998 & 64 \\
1999 & 67 \\
2000 & 250 \\
2001 & 384 \\
2002 & 208 \\
2003 & 155 \\
2004 & 569 \\
2005 & 1,353 \\
2006 & 1,860 \\
2007 & 1,490 \\
2008 & 717 \\
2009 & 1,066 \\
2010 & 1,611 \\
2011 & 2,878 \\
2012 & 672 \\
\hline Total & 13,492 \\
\hline &
\end{tabular}


Table A.3: Number of Biogas Plants by Capacity

\begin{tabular}{lc}
\hline Capacity & Number \\
\hline$x \leq 150 k W$ & 3,407 \\
$150 k W<x \leq 500 k W$ & 6,973 \\
$500 k W<x \leq 5 M W$ & 3,011 \\
$5 M W<x \leq 20 M W$ & 99 \\
$20 M W<x$ & 2 \\
\hline Total & 13,492 \\
\hline
\end{tabular}

Table A.4: Number of Biogas Plants by Precision of Geographical Location

\begin{tabular}{lcc}
\hline Source & Geographical Precision & Number \\
\hline ROOFTOP & Perfect & 7,579 \\
RANGE_INTERPOLATED & Very Good & 1,079 \\
GEOMETRIC_CENTRE & Good & 1,740 \\
BNetzA Anlagenregister & Questionable & 246 \\
APPROXIMATE & Problematic & 2,848 \\
\hline Total & - & 13,492 \\
\hline
\end{tabular}




\title{
Appendix B. Empirical Strategy
}

\author{
Appendix B.1. Treatment and Control Group
}

Table B.1: Balancing Properties After Spatial Matching (Treatment Radius: 2000 Metres)

\begin{tabular}{|c|c|c|c|}
\hline \multirow[b]{2}{*}{ Variables } & \multicolumn{2}{|c|}{ Mean } & \multirow[b]{2}{*}{$\begin{array}{c}\text { Normalised Difference } \\
(\mathrm{T})-(\mathrm{C})\end{array}$} \\
\hline & $\begin{array}{c}\text { Treatment Group } \\
(\mathrm{T})\end{array}$ & $\begin{array}{c}\text { Control Group } \\
\text { (C) }\end{array}$ & \\
\hline Age & 52.9476 & 57.5349 & 0.2056 \\
\hline Is Married & 0.7194 & 0.7382 & 0.0300 \\
\hline Is Divorced & 0.0587 & 0.0623 & 0.0106 \\
\hline Is Widowed & 0.0734 & 0.0834 & 0.0265 \\
\hline Has Very Good Health & 0.0791 & 0.0533 & 0.0736 \\
\hline Has Good Health & 0.3767 & 0.3171 & 0.0886 \\
\hline Has Bad Health & 0.1475 & 0.1869 & 0.0747 \\
\hline Has Very Bad Health & 0.0409 & 0.0436 & 0.0097 \\
\hline Is Disabled & 0.1346 & 0.1716 & 0.0727 \\
\hline Is in School & 0.0159 & 0.0040 & 0.0844 \\
\hline Has Lower Than Secondary Degree & 0.1543 & 0.1426 & 0.0232 \\
\hline Has Tertiary Degree & 0.2671 & 0.3122 & 0.0704 \\
\hline Is in Training & 0.0163 & 0.0074 & 0.0579 \\
\hline Is Part-Time Employed & 0.1147 & 0.0936 & 0.0490 \\
\hline Is Irregularly Employed & 0.0460 & 0.0490 & 0.0102 \\
\hline Is on Parental Leave & 0.0119 & 0.0034 & 0.0692 \\
\hline Is Unemployed & 0.0424 & 0.0283 & 0.0539 \\
\hline Is Out of Labour Force & 0.4753 & 0.5045 & 0.0413 \\
\hline Log Mean Annual Net Household Income & 10.3939 & 10.4384 & 0.0515 \\
\hline Number of Children in Household & 1.7244 & 1.8234 & 0.1686 \\
\hline Number of Rooms Per Individual & 1.8575 & 2.0528 & 0.1373 \\
\hline Lives in Small Apartment Building & 0.1887 & 0.1878 & 0.0016 \\
\hline Lives in Medium-Sized Apartment Building & 0.0914 & 0.0855 & 0.0147 \\
\hline Lives in Large Apartment Building & 0.1507 & 0.1136 & 0.0776 \\
\hline Lives in High Rise & 0.0998 & 0.0951 & 0.0112 \\
\hline Local Unemployment Rate & 9.1778 & 7.8422 & 0.2165 \\
\hline Log Mean Local Household Income ${ }^{a}$ & 7.2796 & 7.3437 & 0.3059 \\
\hline Log Mean Annual Rental Price of Dwelling & 8.8845 & 8.9603 & 0.0991 \\
\hline Number of Observations & & & - \\
\hline Number of Individuals & 1,489 & 13,426 & - \\
\hline
\end{tabular}

${ }^{\mathrm{a}}$ In Euro, Inflation-Adjusted (Base Year 2000), ${ }^{\mathrm{b}}$ Detached, Semi-Detached, Terraced, or Farm House

Notes: The third column shows the normalised difference, which is calculated as $\triangle x=\left(\bar{x}_{t}-\bar{x}_{c}\right) \div$ $\sqrt{\sigma_{t}^{2}+\sigma_{c}^{2}}$, where $\bar{x}_{t}$ and $\bar{x}_{c}$ is the sample mean of the covariate in the treatment and control group, respectively. $\sigma^{2}$ denotes the variance. As a rule of thumb, a normalised difference greater than 0.25 indicates a non-balanced covariate, which may lead to sensitive results (Imbens and Wooldridge, 2009). All figures are rounded to four decimal places.

Source: SOEP (2015), years 2000 to 2012, individuals aged 17 or older, own calculations 


\title{
Appendix C. Results
}

\author{
Appendix C.1. Impacts on Life Satisfaction
}

Appendix C.1.1. Overall Treatment Effect

Table C.1: Results: Overall Treatment Effect (Ex-Ante Excluding Later-Discarded Individuals) Dependent Variable: Satisfaction With Life (Z-Score)

\begin{tabular}{lccccc}
\hline Treatment Radius $r$ in Metres & 1000 & 1500 & 2000 & 2500 & 3000 \\
\hline treat $_{i t, r}$ & -0.0344 & -0.0381 & $-0.0682^{*}$ & -0.0401 & -0.0257 \\
& $(0.0528)$ & $(0.0460)$ & $(0.0370)$ & $(0.0326)$ & $(0.0281)$ \\
\hline Controls & Yes & Yes & Yes & Yes & Yes \\
Year Fixed Effects & Yes & Yes & Yes & Yes & Yes \\
Individual Fixed Effects & Yes & Yes & Yes & Yes & Yes \\
\hline Observations & 43,434 & 45,623 & 49,119 & 53,144 & 57,945 \\
Individuals & 11,833 & 12,165 & 12,675 & 13,279 & 14,002 \\
Individuals in Treatment & 645 & 977 & 1,489 & 2,093 & 2,816 \\
Individuals in Control & 11,188 & 11,188 & 11,186 & 11,186 & 11,186 \\
Adjusted $R^{2}$ & 0.1042 & 0.1041 & 11,186 & 0.1030 & 0.1021 \\
\hline \multicolumn{5}{c}{ Robust standard errors clustered at household level in parentheses } \\
& $* * * p<0.01, * *$ * $p<0.05, *$ p $p<0.1$ &
\end{tabular}

Notes: treat $t_{i t, r}$ is a dummy that equals one if a biogas plant is present inside treatment radius $r$ around the household of individual $i$ in time period $t$, and zero else. We use a ban radius of 3000 metres and a matching radius of 6000 metres. Individuals are allocated to the treatment group if a biogas plant is present inside the treatment radius but not inside the ban radius, and to the control group if a biogas plant is present inside the matching radius but not inside the ban radius (which includes the treatment radius). The control group ex-ante excludes individuals who may be allocated to the control group first but may be discarded later, either because a biogas plant with insufficient geographical precision is constructed inside the treatment radius or a biogas plant (regardless of geographical precision) is constructed inside the ban radius, during the observation period. The outcome is life satisfaction, which has been standardised to have mean zero and standard deviation one. The controls include, among others, the log annual net household income and rental prices (actual rents for renters, estimated rents for owners). See Equation 1 for the model. All numbers are rounded to four decimal places. Source: SOEP (2015), 2000-2012, individuals aged 17 or older, and data on biogas plants described in Section 4.2, own calculations 


\section{Appendix C.1.2. Treatment Effect Intensity}

Table C.2: Results: Treatment Effect Intensity (Treatment Radius: 2000 Metres)

Dependent Variable: Satisfaction With Life (Z-Score)

\begin{tabular}{lcccccc}
\hline Wind Angle $\rho$ in Degrees & 15 & 30 & 45 & 60 & 75 & 90 \\
\hline treat $_{i t, 2000} \times$ wind $_{i, \rho}$ & -0.6654 & -0.3159 & -0.3129 & -0.1209 & -0.0956 & 0.0408 \\
& $(0.6338)$ & $(0.3609)$ & $(0.2776)$ & $(0.2248)$ & $(0.2119)$ & $(0.2187)$ \\
treat $_{i t, 2000}$ & -0.0260 & -0.0294 & -0.0031 & -0.0429 & -0.0436 & -0.1060 \\
& $(0.0661)$ & $(0.0713)$ & $(0.0800)$ & $(0.0843)$ & $(0.0962)$ & $(0.1158)$ \\
\hline Controls & Yes & Yes & Yes & Yes & Yes & Yes \\
Year Fixed Effects & Yes & Yes & Yes & Yes & Yes & Yes \\
Individual Fixed Effects & Yes & Yes & Yes & Yes & Yes & Yes \\
\hline Observations & 64,668 & 64,668 & 64,668 & 64,668 & 64,668 & 64,668 \\
Individuals & 14,927 & 14,927 & 14,927 & 14,927 & 14,927 & 14,927 \\
Individuals in Treatment & 645 & 645 & 645 & 645 & 645 & 645 \\
Individuals in Control & 14,282 & 14,282 & 14,282 & 14,282 & 14,282 & 14,282 \\
Adjusted $R^{2}$ & 0.1006 & 0.1006 & 0.1006 & 0.1006 & 0.1006 & 0.1006 \\
\hline \multicolumn{7}{c}{ Robust standard errors clustered at household level in parentheses } \\
\end{tabular}

Notes: treat $_{i t, r}$ is a dummy that equals one if a biogas plant is present inside treatment radius $r$ around the household of individual $i$ in time period $t$, and zero else. $w_{i n d} d_{i, \rho}$ is a (time-invariant) normalised variable which takes on values between zero and one, indicating the percentage of hours during the day in which the wind is blowing towards a household that is located downwind from the nearest installation. The precise wind angle is given by $\rho$ degrees: for example, $\rho=15$ means that a household is located downwind in a cone that spans $2 \times 15=30$ degrees, opening up 15 degrees from above and 15 degrees from below. We use a ban radius of 3000 metres and a matching radius of 6000 metres. Individuals are allocated to the treatment group if a biogas plant is present inside the treatment radius but not inside the ban radius, and to the control group if a biogas plant is present inside the matching radius but not inside the ban radius (which includes the treatment radius). The control group includes individuals who may be allocated to the control group first but may be discarded later, either because a biogas plant with insufficient geographical precision is constructed inside the treatment radius or a biogas plant (regardless of geographical precision) is constructed inside the ban radius, during the observation period. The outcome is life satisfaction, which has been standardised to have mean zero and standard deviation one. The controls include, among others, the log annual net household income and rental prices (actual rents for renters, estimated rents for owners). See Equation 2 for the model. All numbers are rounded to four decimal places.

Source: SOEP (2015), 2000-2012, individuals aged 17 or older, and data on biogas plants described in Section 4.2 , own calculations 


\section{Appendix C.1.3. Treatment Effect Dynamics}

Table C.3: Results: Treatment Effect Dynamics (Treatment Radius: 2000 Metres)

Dependent Variable: Satisfaction With Life (Z-Score)

\begin{tabular}{|c|c|c|}
\hline & Estimate & Number of Treated Individuals \\
\hline $\operatorname{trans}_{i t+3,2000}$ & $\begin{array}{c}0.0380 \\
(0.0598)\end{array}$ & 1,069 \\
\hline $\operatorname{trans}_{i t+2,2000}$ & $\begin{array}{c}0.1101^{* *} \\
(0.0501)\end{array}$ & 1,211 \\
\hline trans $_{i t+1,2000}$ & $\begin{array}{l}-0.0118 \\
(0.0484)\end{array}$ & 1,454 \\
\hline trans $_{i t, 2000}$ & $\begin{array}{l}-0.0578 \\
(0.0504)\end{array}$ & 1,489 \\
\hline trans $_{i t-1,2000}$ & $\begin{array}{l}-0.0577 \\
(0.0564)\end{array}$ & 1,095 \\
\hline trans $_{i t-2,2000}$ & $\begin{array}{l}-0.0872 \\
(0.0626)\end{array}$ & 859 \\
\hline trans $_{i t-3,2000}$ & $\begin{array}{l}-0.0462 \\
(0.0735)\end{array}$ & 734 \\
\hline trans $_{i t-4,2000}$ & $\begin{array}{l}-0.0275 \\
(0.0647)\end{array}$ & 602 \\
\hline trans $_{i t-5,2000}$ & $\begin{array}{l}-0.0398 \\
(0.0774)\end{array}$ & 434 \\
\hline trans $_{i t-6,2000}$ & $\begin{array}{c}-0.2239^{* *} \\
(0.1057)\end{array}$ & 241 \\
\hline Controls & Yes & \\
\hline Year Fixed Effects & Yes & \\
\hline Individual Fixed Effects & Yes & \\
\hline Observations & 64,541 & \\
\hline Individuals & 14,915 & \\
\hline Individuals in Control & 13,426 & \\
\hline Adjusted $R^{2}$ & 0.1006 & \\
\hline
\end{tabular}

Notes: treat $_{i t, r}$ is a dummy that equals one if a biogas plant is present inside treatment radius $r$ around the household of individual $i$ in time period $t$, and zero else. trans $s_{i t-\tau, r}$ are dummies that equal one in year $t$, which is $\tau$ years after the first biogas plant appears inside the treatment radius, and zero else. We use a ban radius of 3000 metres and a matching radius of 6000 metres. Individuals are allocated to the treatment group if a biogas plant is present inside the treatment radius but not inside the ban radius, and to the control group if a biogas plant is present inside the matching radius but not inside the ban radius (which includes the treatment radius). The control group includes individuals who may be allocated to the control group first but may be discarded later, either because a biogas plant with insufficient geographical precision is constructed inside the treatment radius or a biogas plant (regardless of geographical precision) is constructed inside the ban radius, during the observation period. The outcome is life satisfaction, which has been standardised to have mean zero and standard deviation one. The controls include, among others, the log annual net household income and rental prices (actual rents for renters, estimated rents for house owners). See Equation 3 for the model. All numbers are rounded to four decimal places.

Source: SOEP (2015), 2000-2012, individuals aged 17 or older, and data on biogas plants described in Section 4.2 , own calculations 
Table C.4: Results: Impacts SF12 Physical Health (Z-Scores)

Treatment Radius: 2000 Metres

\begin{tabular}{lcccc}
\hline SF12 Physical Health & Summary Scale & Physical Health & Role-Physical Functioning & Bodily Pain \\
\hline treat $i t, r$ & 0.0539 & 0.3151 & 0.4686 & -0.4339 \\
& $(0.3058)$ & $(0.3719)$ & $(0.4279)$ & $(0.3820)$ \\
\hline Controls & Yes & Yes & Yes & Yes \\
Year Fixed Effects & Yes & Yes & Yes & Yes \\
Individual Fixed Effects & Yes & Yes & Yes & Yes \\
\hline Observations & 26,217 & 26,217 & 26,217 & 26,217 \\
Individuals & 10,329 & 10,329 & 10,329 & 10,329 \\
Individuals in Treatment & 552 & 552 & 552 & 552 \\
Individuals in Control & 9,777 & 9,777 & 9,777 & 9,777 \\
Adjusted $R^{2}$ & 0.4193 & 0.1658 & 0.1745 & 0.1320 \\
\hline
\end{tabular}

Robust standard errors clustered at household level in parentheses

*** $p<0.01,{ }^{* *} p<0.05,{ }^{*} p<0.1$

Notes: treat ${ }_{i t, r}$ is a dummy that equals one if a biogas plant is present inside treatment radius $r$ around the household of individual $i$ in time period $t$, and zero else. We use a ban radius of 3000 metres and a matching radius of 6000 metres. Individuals are allocated to the treatment group if a biogas plant is present inside the treatment radius but not inside the ban radius, and to the control group if a biogas plant is present inside the matching radius but not inside the ban radius (which includes the treatment radius). The control group includes individuals who may be allocated to the control group first but may be discarded later, either because a biogas plant with insufficient geographical precision is constructed inside the treatment radius or a biogas plant (regardless of geographical precision) is constructed inside the ban radius, during the observation period. The physical health outcomes originate from the Short-Form (SF12) Health Survey. The physical health summary scale combines physical health in general, role-physical functioning, and bodily pain. The controls include, among others, the log annual net household income and rental prices (actual rents for renters, estimated rents for owners). See Equation 1 for the model. All numbers are rounded to four decimal places.

Source: SOEP (2015), 2000-2012, individuals aged 17 or older, and data on biogas plants described in Section 4.2, own calculations 
Table C.5: Results: Impacts SF12 Mental Health (Z-Scores)

Treatment Radius: 2000 Metres

\begin{tabular}{lccccc}
\hline SF12 Mental Health & $\begin{array}{c}\text { Summary } \\
\text { Scale }\end{array}$ & $\begin{array}{c}\text { Mental } \\
\text { Health }\end{array}$ & $\begin{array}{c}\text { Role- } \\
\text { Emotional } \\
\text { Functioning }\end{array}$ & $\begin{array}{c}\text { Social } \\
\text { Functioning }\end{array}$ & Vitality \\
\hline treat & & & \\
\hline Controls & -0.0301 & -0.0108 & -0.1729 & 0.2092 & 0.0551 \\
Year Fixed Effects & $(0.3188)$ & $(0.3074)$ & $(0.3205)$ & $(0.3439)$ & $(0.3194)$ \\
Individual Fixed Effects & Yes & Yes & Yes & Yes & Yes \\
\hline Observations & Yes & Yes & Yes & Yes & Yes \\
Individuals & 19,421 & 19,421 & 19,421 & 19,421 & 19,421 \\
Individuals in Treatment & 8,346 & 8,346 & 8,346 & 8,346 & 8,346 \\
Individuals in Control & 1,257 & 1,257 & 1,257 & 1,257 & 1,257 \\
Adjusted $R^{2}$ & 7,089 & 7,089 & 7,089 & 7,089 & 7,089 \\
\hline
\end{tabular}

Robust standard errors clustered at household level in parentheses

$$
\text { *** } p<0.01,{ }^{* *} p<0.05,{ }^{*} p<0.1
$$

Notes: treat $t_{i t, r}$ is a dummy that equals one if a biogas plant is present inside treatment radius $r$ around the household of individual $i$ in time period $t$, and zero else. We use a ban radius of 3000 metres and a matching radius of 6000 metres. Individuals are allocated to the treatment group if a biogas plant is present inside the treatment radius but not inside the ban radius, and to the control group if a biogas plant is present inside the matching radius but not inside the ban radius (which includes the treatment radius). The control group includes individuals who may be allocated to the control group first but may be discarded later, either because a biogas plant with insufficient geographical precision is constructed inside the treatment radius or a biogas plant (regardless of geographical precision) is constructed inside the ban radius, during the observation period. The mental health outcomes originate from the Short-Form (SF12) Health Survey. The mental health summary scale combines mental health in general, role-emotional functioning, social functioning, and vitality. The controls include, among others, the log annual net household income and rental prices (actual rents for renters, estimated rents for owners). See Equation 1 for the model. All numbers are rounded to four decimal places.

Source: SOEP (2015), 2000-2012, individuals aged 17 or older, and data on biogas plants described in Section 4.2, own calculations 
CENTRE FOR ECONOMIC PERFORMANCE

Recent Discussion Papers

\begin{tabular}{|c|c|c|}
\hline 1737 & $\begin{array}{l}\text { Nick Jacob } \\
\text { Giordano Mion }\end{array}$ & The UK's great demand and supply recession \\
\hline 1736 & $\begin{array}{l}\text { Gabriel M. Ahlfeldt } \\
\text { Fabian Bald } \\
\text { Duncan Roth } \\
\text { Tobias Seidel }\end{array}$ & Quality of life in a dynamic spatial model \\
\hline 1735 & Kilian Huber & $\begin{array}{l}\text { Are bigger banks better? Firm-level evidence } \\
\text { from Germany }\end{array}$ \\
\hline 1734 & $\begin{array}{l}\text { César Ducruet } \\
\text { Réka Juhász } \\
\text { Dávid Krisztián Nagy } \\
\text { Claudia Steinwender }\end{array}$ & All aboard: the effects of port development \\
\hline 1733 & $\begin{array}{l}\text { Jonathan Colmer } \\
\text { John Voorheis }\end{array}$ & $\begin{array}{l}\text { The grandkids aren't alright: the } \\
\text { intergenerational effects of prenatal pollution } \\
\text { exposure }\end{array}$ \\
\hline 1732 & $\begin{array}{l}\text { Kabir Dasgupta } \\
\text { André Diegmann } \\
\text { Tom Kirchmaier } \\
\text { Alexander Plum }\end{array}$ & $\begin{array}{l}\text { Heterogeneity in criminal behavior after child } \\
\text { birth: the role of ethnicity }\end{array}$ \\
\hline 1731 & $\begin{array}{l}\text { Andreas Diemer } \\
\text { Tanner Regan }\end{array}$ & $\begin{array}{l}\text { No inventor is an island: social connectedness } \\
\text { and the geography of knowledge flows in the } \\
\text { US }\end{array}$ \\
\hline 1730 & $\begin{array}{l}\text { Hanming Fang } \\
\text { Chunmian Ge } \\
\text { Hanwei Huang } \\
\text { Hongbin Li }\end{array}$ & $\begin{array}{l}\text { Pandemics, global supply chains, and local } \\
\text { labor demand: evidence from } 100 \text { million } \\
\text { posted jobs in China }\end{array}$ \\
\hline 1729 & $\begin{array}{l}\text { Ria Ivandić } \\
\text { Tom Kirchmaier } \\
\text { Ben Linton }\end{array}$ & $\begin{array}{l}\text { Changing patterns of domestic abuse during } \\
\text { COVID-19 lockdown }\end{array}$ \\
\hline
\end{tabular}




\begin{tabular}{|c|c|c|}
\hline 1728 & $\begin{array}{l}\text { Jonathan Colmer } \\
\text { Ralf Martin } \\
\text { Mirabelle Muûls } \\
\text { Ulrich J. Wagner }\end{array}$ & $\begin{array}{l}\text { Does pricing carbon mitigate climate change? } \\
\text { Firm-level evidence from the European Union } \\
\text { emissions trading scheme }\end{array}$ \\
\hline 1727 & $\begin{array}{l}\text { Tony Beatton } \\
\text { Michael P. Kidd } \\
\text { Matteo Sandi }\end{array}$ & School indiscipline and crime \\
\hline 1726 & $\begin{array}{l}\text { Maximilian v. Ehrlich } \\
\text { Henry G. Overman }\end{array}$ & $\begin{array}{l}\text { Place-based policies and spatial disparities } \\
\text { across European cities }\end{array}$ \\
\hline 1725 & $\begin{array}{l}\text { Gabriel M. Ahlfeldt } \\
\text { Thilo N. H. Albers } \\
\text { Kristian Behrens }\end{array}$ & Prime Locations \\
\hline 1724 & $\begin{array}{l}\text { Benjamin Handel } \\
\text { Jonathan Kolstad } \\
\text { Thomas Minten } \\
\text { Johannes Spinnewijn }\end{array}$ & $\begin{array}{l}\text { The Social Determinants of Choice Quality: } \\
\text { Evidence from Health Insurance in the } \\
\text { Netherlands }\end{array}$ \\
\hline 1723 & $\begin{array}{l}\text { Claudia Hupkau } \\
\text { Barbara Petrongolo }\end{array}$ & $\begin{array}{l}\text { Work, Care and Gender During the Covid-19 } \\
\text { Crisis }\end{array}$ \\
\hline 1722 & $\begin{array}{l}\text { Ross Levine } \\
\text { Yona Rubinstein }\end{array}$ & $\begin{array}{l}\text { Selection Into Entrepreneurship and Self- } \\
\text { Employment }\end{array}$ \\
\hline 1721 & Sandra McNally & $\begin{array}{l}\text { Gender Differences in Tertiary Education: } \\
\text { What Explains STEM Participation? }\end{array}$ \\
\hline 1720 & $\begin{array}{l}\text { Edoardo di Porto } \\
\text { Paolo Naticchioni } \\
\text { Vincenzo Scrutinio }\end{array}$ & $\begin{array}{l}\text { Partial Lockdown and the Spread of Covid- } \\
\text { 19: Lessons From the Italian Case }\end{array}$ \\
\hline 1719 & $\begin{array}{l}\text { Swati Dhingra } \\
\text { Stephen Machin }\end{array}$ & The Crisis and Job Guarantees in Urban India \\
\hline
\end{tabular}

The Centre for Economic Performance Publications Unit

Tel: +44 (0)207955 7673 Email info@cep.lse.ac.uk

Website: http://cep.lse.ac.uk Twitter: @CEP_LSE 